\title{
Conformational and Disorder to Order Transitions in Proteins: Structure / Function Correlation in Apolipoproteins
}

\author{
José Campos-Terán ${ }^{1}$, Paola Mendoza-Espinosa², \\ Rolando Castillo ${ }^{3}$ and Jaime Mas-Oliva ${ }^{2}$ \\ ${ }^{1}$ Departamento de Procesos y Tecnología, DCNI, Universidad Autónoma Metropolitana, \\ 2Instituto de Fisiología Celular, Universidad Nacional Autónoma de México, \\ Instituto de Física, Universidad Nacional Autónoma de México \\ México, D.F., México
}

\section{Introduction}

The concept of protein folding is directly related with the process of reversible disorder-toorder transitions, by which an unfolded polypeptide chain folds into a specific functional native structure (Eaton et al., 2000; Rose et al., 2006). For folding into a native state, unfolded polypeptide chains require the intervention of weak interactions. Driven by hydrophobic interactions, a polypeptide chain begins to fold when placed in an aqueous medium, and rapidly becomes a molten globule followed by an important release of latent heat. Stabilization of the molten globule is achieved mainly through the distribution of hydrophobic residues away from the water matrix. On the other hand, because the polar residues contained in a protein develop hydrogen bonds with the water network as well as with each other, a-helices and $\beta$-sheets can be formed when bonds switch between molecules. It has been calculated that such bonds might be in the order of $10^{-12} \mathrm{~s}$, very similar to those we find in water itself. The random equilibrium can be shifted toward one of these conformations by means of two stages: a fast stage, during which the unfolded polypeptide becomes a molten globule; and a slow stage, in which the molten globule slowly transforms into a fully folded form or native state (Huang, 2005). These two stages in protein folding can be illustrated by a "folding funnel", during which due to a small change in entropy with a large loss of energy, a molten globule evolves into the native state (Fig. 1a) (Dobson, 2003; Gsponer \& Vendruscolo, 2006).

Although the process is extremely efficient, there is always the possibility that this accurate mechanism might fail, and the possibility of finding a protein folded into a non-native state becomes a reality (Dobson, 1999). Proteins that follow this pathway might present transiently stable conformations, promoting their interaction with other molecules and facilitating the fact that they might form amorphous oligomers and end in a state of aggregation. Aggregation does not arise from a random coil state, but rather from a series of intermediates that-based on the type of secondary structure acquired during folding- 
might or might not resemble the native state (Fig. 1b) (D. Eisenberg et al., 2006, Gsponer \& Vendruscolo, 2006). It is well known now that primary polypeptide sequences become the key factor during this process, while the environment surrounding the protein is an important factor for explaining the folding process (Fink, 1998). On the other hand, natively unfolded proteins, known to lack the presence of permanent secondary and tertiary structures, have been recognized at least in the absence of other proteins, to present the tendency to organize themselves into amyloidogenic structures. Considering that the native state is located at the lowest minimum of the "folding funnel", it indicates that this region is the most thermodynamically stable configuration of the polypeptide chain under physiological conditions. For proteins, whose functional state is a tightly packed globular fold, a key step in fibril formation related to partial or complete unfolding is less likely to occur and therefore remains protected against aggregation (Dobson, 2004). In this respect, it has been proposed that the more transient structures thus formed in proteins, the better probability for key determinants in amyloid fibril formation to be found (Ohnishi \& Takano, 2004). Thus, many of the known forms of amyloid diseases associated with genetic mutations that decrease protein stability and promote unfolding (Ohnishi \& Takano, 2004), are both related to disorder-to-order conformational transitions.

The first experimental evidence about a specific disorder-to-order transition was presented over 30 years ago with the mechanism description for the conversion of trypsinogen to trypsin (Bode \& Huber, 1976). This mechanism is characterized by the enzymatic removal of a hexapeptide from the N-terminal region of trypsinogen in order to form trypsin. This basic change promotes the transition from a disordered state of the "specificity pocket" in trypsinogen to an ordered state in trypsin (Huber \& Bode, 1978). Since it is known that several amino acids that make up a protein strongly favor a disordered state, at present this "new view" of folding is beginning to be further studied, in which the influence of external or environmental conditions sustains well-tested transitions between disordered and ordered states. Specific polypeptide chains contained in proteins or complete proteins

a)

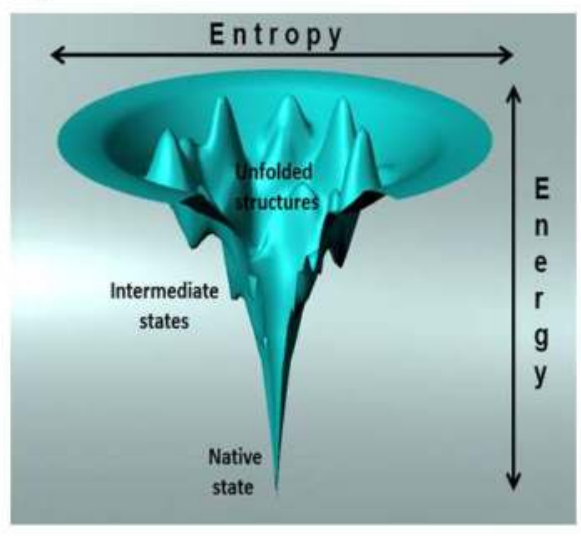

b)

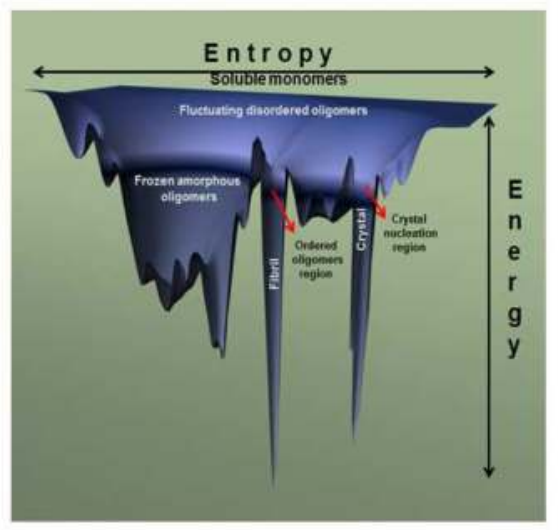

Fig. 1. a) Folding funnel energy landscape b) Protein aggregation energy landscape. 
lacking defined tertiary structures are known to have the capacity to undergo disorder-toorder transitions upon binding to specific (Tompa, 2002) or multiple partners (James \& Tawfik, 2003). It is precisely this ability that allows the concept of "protein disorder" to be proposed as an important feature in the capability of proteins to present regions with switching properties (Bustos \& Iglesias, 2006; Dalal \& Regan, 2000; Kriwacki et al., 1996).

From an evolutionary point of view, it appears that intrinsic disorder in proteins might have been the driving force behind many of the adaptability processes found in proteins (Dobson, 1999; Dunker et al., 1998). Taking into account that the number of proteins presenting disordered regions directly related with function and therefore with disease is increasingly growing, an interest to also generate accessible data banks for improving information management has increased. Therefore, the database of disordered proteins (DisProt) was created and released in August 2006 by the group of Dunker (Sickmeier et al., 2007) with extremely good results at present (Cortese et al., 2008). Since then, other systems for studying disorder in proteins have been released, such as the Integrated Protein Disorder Analyzer, which aims at identifying and predicting disordered region in proteins (Su et al., 2007), or algorithms for predicting and evaluating aggregation "hot spots" (AGGRESCAN) (Conchillo-Sole' et al., 2007). According to Dunker's group and as predicted by the Predictor of Natural Disordered Regions (PONDR) server (Romero et al., 2001), a large percentage of all proteins involved with some sort of a disease have been identified as directly related with disordered regions in proteins closely associated with signaling. From a general point of view, disordered regions in proteins have been divided into the following two classes: the class in which proteins retain a low percentage of secondary structure together with unstable tertiary structures during a molten globule state, recognized as the collapsed class; and second, the extended class in which proteins with a highly extended backbone resemble a $\beta$-sheet conformation (Dunker et al., 2001; Uversky, 2002).

In general, proteins containing disordered regions have been recognized as associated with several human diseases, including cardiovascular disease, cancer, degenerative diseases, and diabetes. Interestingly, because in many of these cases cell signaling function has been involved, there is a strong possibility that disorder-to-order transitions in proteins playing normal switching roles in the cell might become distorted and therefore abolish or transform the normal protein-protein language into an aberrant one. Therefore, the basic properties of a switching mechanism must be based on the equilibrium between high specificity and weak affinities accompanied by a large conformational entropy decrease. This phenomenon is based principally on the fact that upon binding, disorder-to-order transitions can overcome steric restrictions and thereby enable larger interaction surfaces in protein-protein complexes than those that could be obtained for rigid partners. Despite the extraordinary importance of this type of transition, we continue to lack detailed biophysical studies that might demonstrate a close relationship between this type of disorder-to-order organization and protein function.

In an attempt to define the possibility that folding key features in proteins could provide us with the manner in which to explain basic issues such as receptor recognition, lipid transfer activity, and self-exchangeability carried out by several lipid transfer proteins including Apolipoproteins (Apos), our group has attempted to address these points by directly measuring molecular conformational changes of Apos at air/water and lipid/water 
interfaces, in order to approach the possible mechanisms that might explain these phenomena (Xicohtencatl-Cortes et al., 2004a, 2004b). As described below, this has been achieved employing Langmuir monolayers in conjunction with Brewster angle microscopy (BAM), atomic force microscopy (AFM) of Apos LB films (Bolaños-García et al., 1999, 2001; Mas-Oliva et al., 2003; Xicohtencatl-Cortes et al., 2004a), grazing incidence X-ray diffraction on protein monolayers (Ruíz-García et al., 2003), and surface force measurements (SFA) (Campos-Terán et al., 2004; Ramos et al., 2008). Because at that time, we were unable to define whether the secondary structure of specific segments of Apolipoprotein CI (ApoCI) and AII (Apo AII) remained stable independently of their position at air/water and lipid/water interfaces, recently we have addressed the possibility that these segments responding to specific environmental changes and following disorder-to-order transitions might function as molecular switches that trigger function (Mendoza-Espinosa et al., 2008, 2009). Moreover, following the same approach with specific peptides synthesized from the reported structure of Apolipoprotein AI (Apo AI), we have found that when left in water at $4^{\circ} \mathrm{C}$ a very slow disorder-to-order transition develops over the course of days, from a fully disordered state to a well-developed $\beta$-sheet secondary structure. This behavior further supports the fact that the physicochemical characteristics of the environment must be considered as a key factor in the equilibrium displacement within the secondary structure of a protein or specific segments toward a-helices or $\beta$-sheets (Andreola et al., 2003). Here, the result that specific segments of Apo AI slowly develop fibril-like structures indicates the possibility that pathological processes such as atherogenesis might be also considered as an amyloidotic-related process (Fig. 2) (Mendoza-Espinosa et al., 2009; Westermark et al., 1995). New results related to these studies are also described in this chapter.

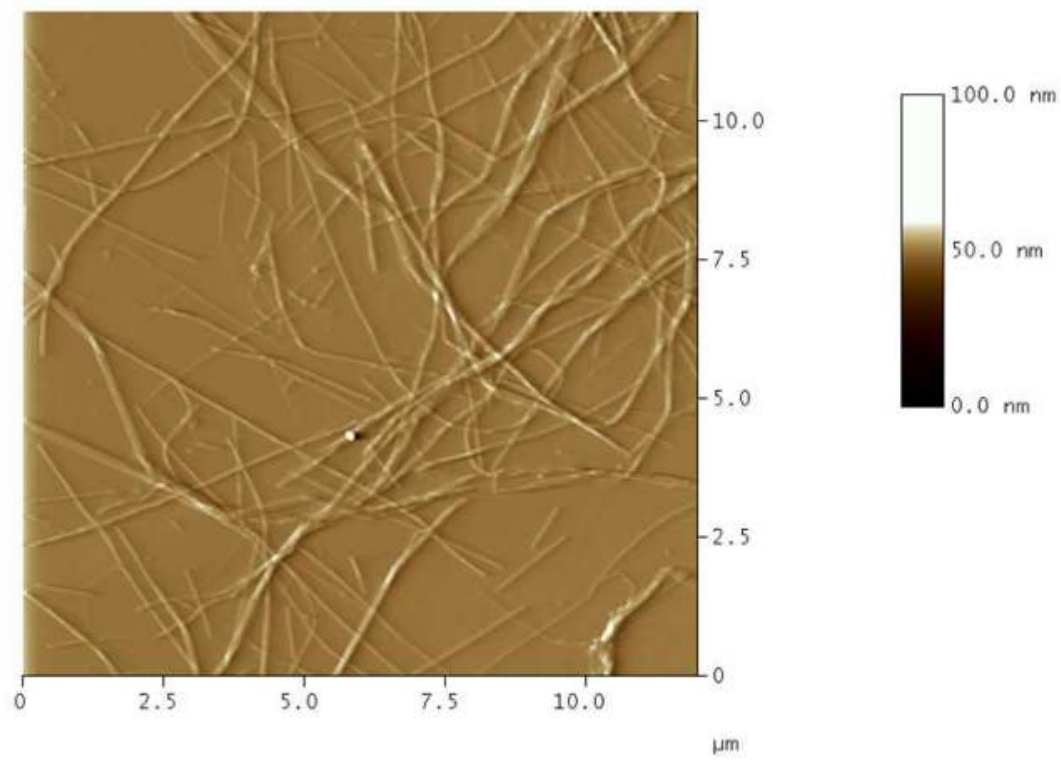

Fig. 2. Atomic force microscopy image $(12 \times 12 \mu \mathrm{m})$ of apolipoprotein AI-peptide DRV fibrils (amino acids 9-24). Fibrils show an average length of $300 \mathrm{~nm}$ and $25 \mathrm{~nm}$ in height. 


\section{Structural characteristics of Apolipoproteins $\mathrm{Cl}$, All and Al}

Apolipoproteins (Apos) are membrane active proteins that are constituents of highdensity lipoproteins (HDL), which are related to the reverse cholesterol transport (Despres et al., 2000). These proteins have an amphiphilic character, since a polar protein face is formed by charged amino acid residues clustered on one side of the a-helices, whereas a hydrophobic surface composed of non-polar residues is formed at the opposite face (Bolaños-García et al., 1997). When Apos are in contact with a polar/non-polar media, their natural tendency is to anchor the hydrophilic and hydrophobic regions in the polar and in the non-polar media, respectively. Thus, a hydrophobic/hydrophilic interface tends to induce a specific orientation on the adsorbed molecules. Some lipoprotein-bound Apos are able to dissociate from the lipoprotein surface in a lipid-poor form, and then transferred through the plasma serum to other lipoproteins (Castro \& Fielding, 1984; Clay et al., 1999; Liang et al., 1995; Wang, 2002; Weinberg \& Spector, 1985). Although, this mechanism is poorly understood, it is known to be conducted by interactions between Apolipoproteins located at the lipid surface. Apo CI, AII and AI are members of this family of proteins that apparently give lipoproteins directionality and the ability to interact with receptors at the surface of cells.

Apo CI is composed of 57 amino acid residues in length, with a molecular mass of 6.63 KDa. This protein plays a key role in the chylomicron uptake (S. Eisenberg, 1990) and in the regulation of apolipoprotein-E/ $\beta$-VLDL (very low-density lipoproteins) particle interaction (Swaney \& Weisgraber, 1994). Secondary structure predictions, nuclear magnetic resonance, and circular dichroism studies made on Apo CI have revealed a high a-helix content, distributed in two a-helices (Bolaños-García et al., 1999). The first a-helix (residues 4-30) presents approximately 7.5 periods, while the second one (residues 35-53) consists of 5.2 periods (see Fig. 3). In addition both a-helices present important hydrophobic moments $(\mu \mathrm{H})$ (Bolaños-García et al., 1999). Apo AII is the second major apolipoprotein of highdensity lipoproteins (HDL) and it is synthesized in the liver (Eggerman et al., 1991). This protein has been suggested as a modulator of reverse cholesterol transport rather than a strong determinant of lipid metabolism (Tailleux et al., 2002). Apo AII is formed by two identical polypeptide chains connected by a disulfide bridge at position 6 , where each chain corresponds to 77 amino acid residues in length and a molecular mass of $8.708 \mathrm{kDa}$ (Brewer et al., 1972, 1986). Predictive and circular dichroism studies (Bolaños-García et al., 1997, 2001), as well as high-resolution crystal structure studies (Kumar et al., 2002) have shown that each chain of the Apo AII presents two a-helix motifs (segments encompassing 7-27 and 32-67) as its main secondary structure (see Fig. 3). These a-helices present an important hydrophobic moment, have approximately 31.5 and $54 \AA$ in length and they are connected by a short peptide chain as a loose hinge (Bolaños-García et al., 2001). Correlation between protein stability to thermal denaturation and secondary structure content has also been investigated (Bolaños-García et al., 2001).

Apo AI has been studied in its free state and membrane models due to the importance that involves understanding the processes that give rise to nascent HDL, as well as the precise mechanisms that support these phenomena in relationship with the process of reverse cholesterol transport. The 243 amino acid polypeptide chain of the Apo AI is organized in blocks of 22 and 11 residues, which are predicted to form helix-type amphipathic 


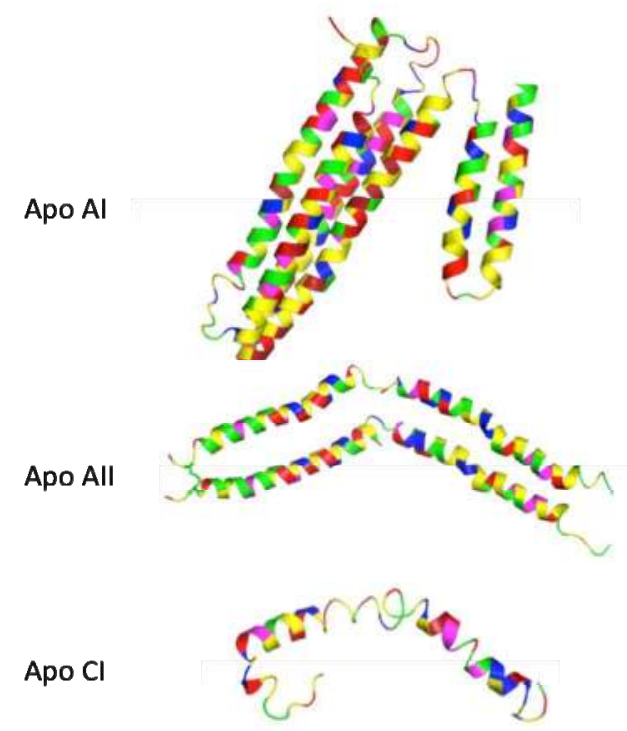

Fig. 3. Secondary structure images of Apolipoproteins showing their a-helical conformation. The color code for the residues is as follows: aromatic-magenta, aliphatic-yellow, polar non charged-green, positively charged-blue, negatively charged-red.

segments (see Fig. 3). The helices that make up the Apo AI, have been classified as follows: (145 aа) $G^{*},\left(44-65,66-87,121-142,143-164,165-186,187-208\right.$ aa) $A_{1},(88-98,99-120,209-219,220-241)$ Y. Helices classified as type $G$ correspond to amphipathic helices that form the interior of globular proteins, reason why amino acids they contain correspond to a hydrophobic type character. Amphipathic helices of the $\mathrm{A}_{1}$ type have as a characteristic the presence of positively charged amino acids at the hydrophobic/hydrophilic interface, while the negative residues are in the center of the polar face. On the other hand, Y-type helices present the characteristic of having positive charged aminoacids separated by negative ones (Segrest et al., 1992). Currently, there are two crystal structures of the lipid-free Apo AI in different conformations. In the crystal structure obtained by Borhani et al. ( $\Delta 1-43)$ (Borhani et al., 1997), the N-terminal segment is truncated. This structure is unique in presenting a conformation similar to the one that would be in the presence of lipids. Also, the Apo AI (1243) structure obtained by Ajees et al. (Ajees et al., 2006), presents two domains formed by four a-helices in the $\mathrm{N}$-terminal and 2 a-helices in the C-terminus. Spectroscopic techniques have shown that the lipid-free Apo AI in solution presents a three-dimensional arrangement in two domains similar to that observed in the crystal structure, but with much less organization (Tanaka et al., 2008).

\section{Monolayer behavior of Apolipoproteins}

When Apolipoproteins are in contact with a polar/non-polar media, they will anchor the hydrophilic and hydrophobic regions in the polar and in the non-polar media, respectively. Thus, a hydrophobic/hydrophilic interface tends to induce a specific orientation on the 
adsorbed proteins. As mentioned, Apo CI, AII and AI are associated with lipoproteins particles that are modeled (Borhani et al., 1997) as spheres with a shell of a phospholipid monolayer, with the polar head groups oriented towards the aqueous phase, and the core consists of triglycerides and cholesterol esters (hydrophobic region). In these models, Apos are usually oriented parallel to the surface of the lipoprotein particles. A way to understand the behavior of Apos on the lipoprotein surface is to deposit them on an interface that models the lipoprotein surface, which could be increasingly complex as needed.

The first attempts in this direction have used Apo CI and AII Langmuir monolayers deposited at the air/water interface (Bolaños-García et al., 1999, 2001). For both proteins the compression isotherm showed two first-order phase transitions (see Fig. 4). The first one corresponds to the coexistence between a liquid (L) and a gaseous $(\mathrm{G})$ phase where the proteins have low interaction. The second transition involves two condensed phases; the liquid phase, L, and a condensed phase denoted by LC. For the case of Apo CI, this second transition occurs at a surface pressure (П) of approximately $33 \mathrm{mNm}^{-1}$ and at an area (A) between 350 and $600 \AA^{2}$ /molecule. For Apo AII it was found at $\Pi \sim 30-35 \mathrm{mNm}^{-1}$ and

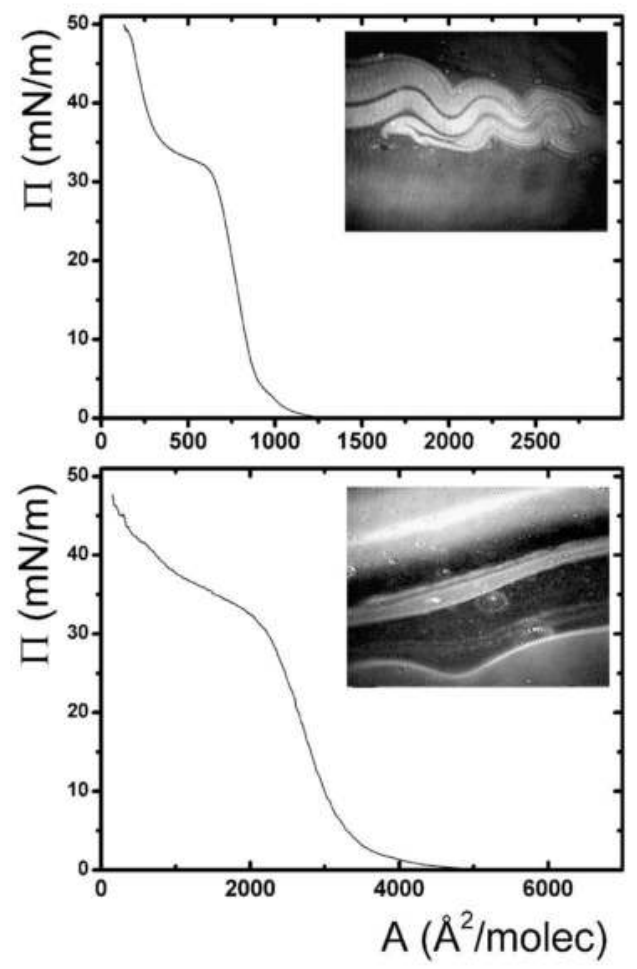

Fig. 4. Langmuir monolayer isotherms of Apo CI (upper panel) and Apo AII (lower panel) at $25.1{ }^{\circ} \mathrm{C}$. Both proteins were dispersed over a phosphate buffer subphase $(\mathrm{pH}=8.0)$ containing $3.5 \mathrm{M} \mathrm{KCl}$. Insets show BAM images at the L-LC coexistence. Adapted from (XicohtencatlCortes et al., 2004a). 
A 1000-2500 $\AA^{2} /$ molecule. Brewster angle microscopy (BAM) images taken this transition showed the L phase as dark regions while the LC phase was clearly observed as very bright domains. In the liquid phase, the protein configurations are restricted to a horizontal orientation at the interface due to the amphiphilic character of these proteins. As the surface area is decreased on isothermal compression, one of the a-helix segments for the case of Apo $\mathrm{CI}$ and two for Apo AII are expelled from the interface. Direct evidence of this conformational change, as well as of the a-helix structure of Apo CI and AII, have been shown using grazing incidence X-ray diffraction and atomic force microscopy (AFM) of Langmuir-Blodgett (LB) films of transferred protein monolayers (Ruíz-García et al., 2003). It is important to mention that a similar behavior was observed for Apo AI (Bolaños-García et al., 2001).

Experiments on more complex interfaces that are closer to the lipoprotein surface have been prepared adsorbing Apo CI and AII on rac-1,2-dipalmitoyl-sn-glycero-3-phosphocholine (DPPC) monolayers, which indicate that Apolipoproteins can penetrate the DPPC monolayer to form part of the monolayer at the air/water interface (Xicohtencatl-Cortes et al., 2004a). These monolayers also present two clear phase transitions between condensed phases, as well as one between a condensed phase and a gas phase. In this case, the Langmuir monolayer and BAM observations revealed that below surface pressures of $10 \mathrm{mN} / \mathrm{m}$ it was possible to have a 2D isotropic mixture where the surface area of the monolayer was approximately the sum of the area occupied respectively by the protein and DPPC molecules as if they were pure components. As the surface pressure is increased and it reaches the condensed phase transition at $\Pi \sim 24-31 \mathrm{mNm}^{-1}$ there is a important loss of monolayer area with an increasing brightness in one of the condensed phases, as seen with BAM images (see Fig. 5). Taking into account this observations and that the $\Pi$ values for this condensed transition of the
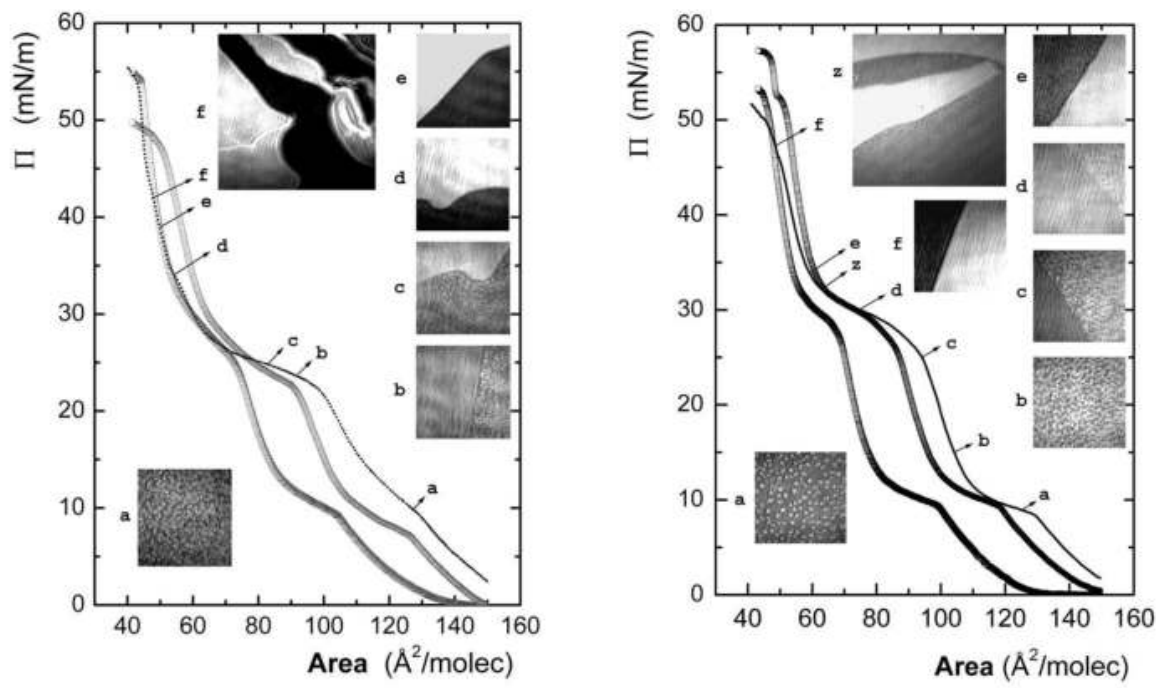

Fig. 5. Langmuir isotherms for Apo CI/DPPC (left, nominal protein mole fraction, from left to right $\mathrm{x}=0.04,0.05,0.12$ ) and Apo AII/DPPC (right, nominal protein mole fraction, from left to right $x=0.01,0.02,0.03)$. Insets shows BAM images at different lateral pressures. Adapted from (Xicohtencatl-Cortes et al., 2004a). 
binary system are similar to the ones found for the proteins as single components, it was proposed that here there was also a conformational change of the Apo where a-helix segments desorb from the interface, aligning and following the DPPC tails inclination (Xicohtencatl-Cortes et al., 2004a).

\section{Forces between adsorbed layers of Apolipoproteins}

\subsection{The surface force apparatus technique}

Forces that control the interaction between proteins, proteins and surfaces and surfaces with adsorbed proteins, are the result of different contributions as hydrophobic interaction, entropy gain due to counterion release, van der Waals force, and to a large extent electrostatic interactions, where the latter is governed by variables like $\mathrm{pH}$ and salt concentration. All these interactions depend on the kind of surface and solution where the proteins are immersed, as well as on their charge, shape, and conformation. The surface force apparatus (SFA) (Israelachvili, 1973; Parker et al., 1989) offers the possibility of measuring long-range and contact forces between two mica surfaces covered with adsorbed proteins (Claesson et al., 1995), as well as, measuring the absorbed layer thickness and its compressibility. The latter parameter can give information about the conformational structure and size of the adsorbed protein.

The SFA instrument and experimental procedures have been described by Israelachvili (Israelachvili \& McGuiggan, 1990) and Parker (Parker et al., 1989). In general, the force is measured between two curved molecularly smooth mica surfaces (typically $1 \mathrm{~cm}^{2}$ of area with 2-5 $\mu \mathrm{m}$ constant thickness) where a silver layer of about $520 \AA$ thick was deposited through evaporation on one side of each surface. After that the mica pieces are glued with an epoxy resin, with the silver side down, onto optically polished half-cylindrical silica disks (mean radius of curvature, $\mathrm{R}, \sim 1-2 \mathrm{~cm}$ ) that are finally mounted in a crossed cylinder configuration on the SFA. Here, one of the disks is mounted on a double cantilever spring (spring constant, $\mathrm{k}, \sim 105 \mathrm{~N} / \mathrm{m}$ ) and the second one on a piezoelectric crystal. This setup produces an optical interferometer. The separation between the two surfaces, $d$, is controlled by the piezoelectric crystal and the absolute distance is measured interferometrically using fringes of equal chromatic order (FECO) with an accuracy of $2 \AA$. The magnitude of the force, $\mathrm{F}$, as a function of the surface separation, normalized with respect to the mean radius of curvature, can be determined from the spring deflection measured down to ca. $10^{-7} \mathrm{~N}$. Usually, a SFA experiment starts with the measurement of a standard force curve of water or a buffer solution. If the surfaces contact position is clean and the force curve measured is consistent with the theoretical Derjaguin, Landau, Verwey and Overbeek (DLVO) theory predictions, a known amount of protein is added to the SFA chamber to allow a slow adsorption to the surfaces from the surrounding solution. Then the force curves are usually measured at different times to evaluate this protein adsorption process.

With the SFA, as with other force measurement techniques, one has to consider that the comparison between theoretical and experimental force curves is not straightforward, since the measured force is the sum of different contributions, which are interrelated and therefore not easy to separate. In general, the electrostatic-double layer and the van der Waals forces are considered the most important contributions. However, an absolute 
determination of the magnitude of each of these forces is complex, due to factors as protein and surface charge density, protein concentration and solution ionic strength, contribution from steric interactions at short distances, etc. In addition, the location of the plane of charge and the dielectric properties of the adsorbed protein layer usually cannot be determined unambiguously. Nevertheless, the results from SFA studies of the interaction between layers of globular proteins, like insulin and lysozyme, and of proteins with disordered structures have increased our knowledge on the proteins adsorbed layer structure (Claesson et al., 1995). This also includes our SFA studies with proteins formed mainly by a-helices, which will be described below.

\subsection{Force measurements with Apolipoproteins deposited on hydrophilic surfaces}

In general, the force curves measured between hydrophilic surfaces with adsorbed layers of Apos are mainly composed of electrostatic double layer forces at large surface separations and of steric repulsive forces at small distances. These steric forces are quite interesting since they give some insights of the preferred Apos conformations and the interaction produced by them. Apos amphiphatic structure produces a directional adsorption where the hydrophilic faces of the protein a-helices prefer to be adsorbed onto the mica leaving the hydrophobic faces of the a-helices in contact with water. As an example, figure 6 shows the force curves measured, using a SFA, between two mica surfaces adsorbed with Apo AII. In this case, the adsorption was produced from the protein buffer solution (acetic acid-sodium acetate, $\mathrm{pH}=4$ ) that surrounds the surfaces. Also, a sequential increment of the protein concentration from 0.002 to $0.004 \mathrm{mg} / \mathrm{mL}$ was produced to observe the effect in the surface adsorption (Ramos et al., 2008).

As it can be observed, no forces were found until a surface separation of $700 \AA$ was reached. From there, if the surfaces are brought together, a long-range repulsive force is observed until it is overcome by an attractive force (inward jump), which brings the surfaces from a surface separation of about $130-200 \AA$ into a closer contact. The surface separation where the attractive force drives the surfaces close together decreases with adsorption time and it disappears if the protein concentration is increased (see the force curves with $0.004 \mathrm{mg} / \mathrm{mL}$ after $8 \mathrm{hrs}$ of adsorption). In some cases, a small repulsive force was found before reaching a repulsive hard wall. The hard wall at the lower concentration was found to be at a surface separation, $d$, of $11 \AA$. Interestingly, when the protein concentration was increased (to 0.004 $\mathrm{mg} / \mathrm{mL}$ ) the surface separation value for the hard wall increases with protein adsorption time with approximately $10 \AA$ increments. Also, an adhesive pull-force was found when the surfaces are taken apart, which decreases with protein adsorption. It was also observed that the force curves were the same on compression and on separation if the surfaces are not brought closer than the inward jump. Similar force curves were found for Apo CI (CamposTerán et al., 2004).

In this case, the long-range repulsive force and the attractive force can be fitted using DLVO theory including additive contributions of non-retarded van der Waals forces and the electrostatic double layer force (see Fig. 6). Calculations of double layer force were performed with the algorithm of Chan et al. (Chan et al., 1980) bringing into play both constant surface potential and constant surface charge. In practice, it is most likely that both potential and surface charge vary as the surfaces approach, where the actual double layer 
force, as it is in this case, falls between these two limits due to the proteins charge regulation. Although DLVO theory does not take into account additional forces occurring between the surfaces, e. g., hydration forces, hydrophobic forces, and steric forces, etc., the fitting is quite good, and the attractive force measured is close to what theory suggests, at constant surface potential.

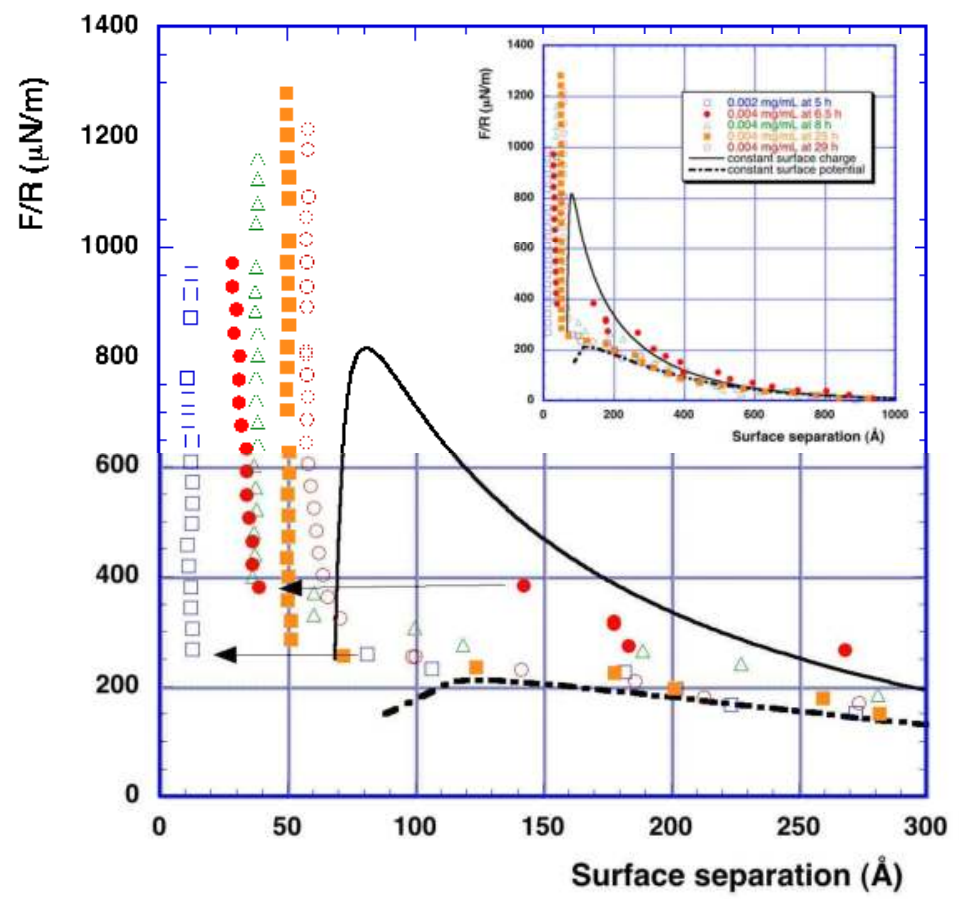

Fig. 6. Force normalized by the radius of curvature, F/R, as a function of surface separation and total adsorption time between mica surfaces adsorbed with Apo AII. The total protein concentration was increased at two times during the experiment and it is: $0.002 \mathrm{mg} / \mathrm{mL}$ at 5 $\mathrm{h}(\square), 0.004 \mathrm{mg} / \mathrm{ml}$ : at $6 \frac{1}{2} \mathrm{~h}(\bullet)$, at $8 \mathrm{~h}(\Delta)$, and $25 \mathrm{~h}(\mathbf{\bullet}), 29 \mathrm{~h}(\circ)$. Lines indicate DLVO fitting $(0.004 \mathrm{mg} / \mathrm{ml})$ with constant surface charge and dashed lines with constant surface potential. Arrows indicate attractive jumps. Adapted from (Ramos et al., 2008).

\subsubsection{Short-range forces probe the orientation of the adsorbed protein}

As mention before, the analysis of the measured force curves can give an insight of the protein conformation at the surfaces. For the case described above it was seen that the average distance where attractive force appears, $d \sim 150 \AA$, is close to double of the maximum length of this proteins $(\sim 85 \AA)$, which suggests that entire protein is oriented perpendicular to the surface or that individual protein segments, i. e, a-helices, protrudes from them. These protein segments could take part in bridging between the two surfaces and thus be responsible for the attractive force. This kind of attractive force was also observed in adsorbed surfaces with Apo CI (Campos-Terán et al., 2004). In addition, studies of Apo AII 
and Apo CI monolayers have shown that it is possible to form a layer with protruding segments at an interface (Bolaños-García et al., 2001; Ruíz-García et al., 2003). The fact that at short adsorption time, it was observed a weak repulsive force, suggests a more extended conformation of the adsorbed proteins. Such protruding segments could be compressed, bearing in mind the relative flexibility of the polypeptide chains connecting the a-helices. Given enough time for adsorption, the protein molecule preferentially will be oriented parallel to the surface and hence, this repulsive force disappears. The driving force for protein reorientation is to avoid the exposure of hydrophobic segments to the aqueous environment, as well as to promote the electrostatic attractive interactions between the protein and the surface. At low concentrations, the attractive interaction is reduced with time, which implies a higher protein surface coverage confined in a thin layer. This thin protein layer was found experimentally since it was found a surface separation of just $11 \AA$ at the hard wall position. This final layer thickness value is between 5 to $6 \AA$ on each surface, which is similar to the estimated value for a-helices diameter. Previously, it has been shown that structural changes on adsorption are not enough to disturb the a-helix structure (Burkett \& Read, 2001).

\subsubsection{Sequential addition of Apos builds up protein multilayers}

Experiments conducted at higher concentrations suggest the build up of more than one layer on each surface since each curve shown in figure 5 represents an increase in hard-wall separation of $\sim 10 \AA$ or approximately $5 \AA$ of thickness on each surface (see Fig. 6). Confirmation of this process was obtained by ellipsometry measurements done by our group (Ramos et al., 2008), which showed that sequential addition of protein (at least at high ionic strength) leads to an increase in the adsorbed amount of protein, as well as the protein layer thickness. However, for the case of Apo AII, the presence of a repulsive interaction showed that protein adsorption do not lead to charge neutralization of the mica surface charge as it was found for Apo CI (Campos-Terán et al., 2004). This is most likely due to the structural difference between both proteins, where the Apo CI monomer can more efficiently arrange so that it better match the surface charge compare to the Apo AII dimer. However, since the apparent surface potential has a small change when the protein concentration is increased from $0.002 \mathrm{mg} / \mathrm{ml}$ to $0.004 \mathrm{mg} / \mathrm{ml}$, a charge regulation mechanism involving small ions during the adsorption of the proteins cannot be discarded. This mechanism has been observed to occur in the surface adsorption of other proteins (Claesson et al., 1995). Protein multilayer adsorption has been observed in proteins with amphiphilic or flexible segments, as observed at SFA experiments with cytochrome c (Kekicheff et al., 1990) and $\beta$-casein (Nylander \& Wahlgren, 1997). A multilayer protein adsorption requires attractive protein-protein interaction, which often is weaker than the protein-surface interactions. Confirmation of this statement was obtained by diluting the solution surrounding the surfaces. Here, the hard wall separation decreased from $d \approx 58 \AA$ to $\mathrm{d} \approx 26 \AA$ and the apparent surface potential has increased from $\sim 37 \mathrm{mV}$ to $\sim 53 \mathrm{mV} 1 \frac{1 / 2}{\mathrm{~h}}$ after dilution, which indicates protein desorption. Even more protein has desorbed after 18 $\mathrm{h}$, and the hard-wall separation reaches $\mathrm{d} \approx 11 \AA$, corresponding to one monolayer on each surface. In addition, an attractive jump appears. No further desorption occurs, which is mostly likely due to the strong interaction between the negatively charged mica and the cationic protein as well as the entropy gain due to counter ion release. This experiment 
showed the reversibility of Apo AII adsorption process that produces in each stage different protein conformations. Also, it is noteworthy that quite similar force curves were observed in Apo CI (Campos-Terán et al., 2004), which also has a similar secondary structure but with a different peptide sequence, different net charge, and it is only monomeric. Therefore, the observed force curves seem to be a consequence of the particular features of the amphiphilic a-helices.

\section{Lipid dependant disorder-to-order conformational transitions in Apolipoproteins}

\subsection{Apo Cl derived peptides-lipid interaction}

As mentioned in sections 3 and 4, it has been observed for exchangeable Apolipoproteins that when they are subjected to lateral pressures then several helical segments were placed directly in the hydrophobic phase of the interface. In the case of Apo CI, our data showed an interesting new property since we observed that injecting it into the subphase allows the protein to go to the water/lipid interface quickly and when lateral pressure is increased the C-terminal helical segment penetrates the monolayer. In addition, when lateral pressure is released, this segment is again incorporated into the water/lipid interface (Bolaños-García et al., 1999). With these results we were interested to know if the secondary structure of the Cterminal segment of Apo CI remained stable regardless of their position in the different hydrophilic/hydrophobic interfaces. To solve this question we conducted studies of peptides derived from the C-terminal segment of Apo CI in different environments.

The peptides were designated according to the first three letters of their amino acid sequence and called ALDO (A7-E24), ARELI (A22-M38) and SAK (S35-L53). Apo CI in solution shows a clear circular dichroism (CD) signal associated with a high degree of ahelix structure (Bolaños-García et al., 1999). However, when peptides ALDO, ARELI and SAK (Mendoza-Espinosa et al., 2008) were tested under the same experimental conditions, they showed no defined secondary structure and remain non-structured independently of $\mathrm{pH}$, temperature and ionic strength. Interestingly, despite that these peptides have an amphipathic character and high hydrophobic moment values $(\mu \mathrm{H}>0.315 \mathrm{kcal} / \mathrm{mol})$, they remain completely unfolded in solution (see Fig. 7a).

Nevertheless, when peptides ALDO, SAK and ARELI are placed in aqueous solution with $40 \% \mathrm{v} / \mathrm{v}$ trifluoroethanol (TFE) or sodium dodecylsulphate (SDS, cmc of $8.5 \mathrm{mM}$ ) they show a CD signal clearly associated with an a-helical structure. If SDS was used at different concentrations (1.5-20 mM), each of the peptides acquire secondary structures in a differentiated way, where the lowest percentage of a-helix structure corresponds to ARELI and the highest to SAK peptide, which corresponds to the C-terminal segment of Apo CI (see Figs. $7 \mathrm{~b}$ and $7 \mathrm{c}$ ). Then in order to test the possibility that specific lipids on the surface of lipoproteins and plasma membrane induce an a-helix conformation as in the case of TFE and SDS, we tested a series of phospholipids above and below its critical micelle concentration and with different acyl long chain to probe their hydrophobic effect. L-aPhosphatidylcholine (PC) was used above its critical micellar concentration $(\mathrm{cmc}<0.005$ $\mathrm{mM}$ ) and 1,2-dihexanoyl-sn-glycero-3-phosphocholine (DHPC) slightly below its cmc ( 15 $\mathrm{mM})$, because concentrations above the $\mathrm{cmc}$ of DHPC generate solutions that prevent the 
determination of the CD signal (data not shown). Under these conditions, only peptide SAK showed a well-defined disorder to order type transition. Since medium hydrophobicity seems to be critical for the transition to be observed, we tested if these lipids mixed with small amounts of cholesterol altered these low percentages of a-helix, finding no changes (data not shown).
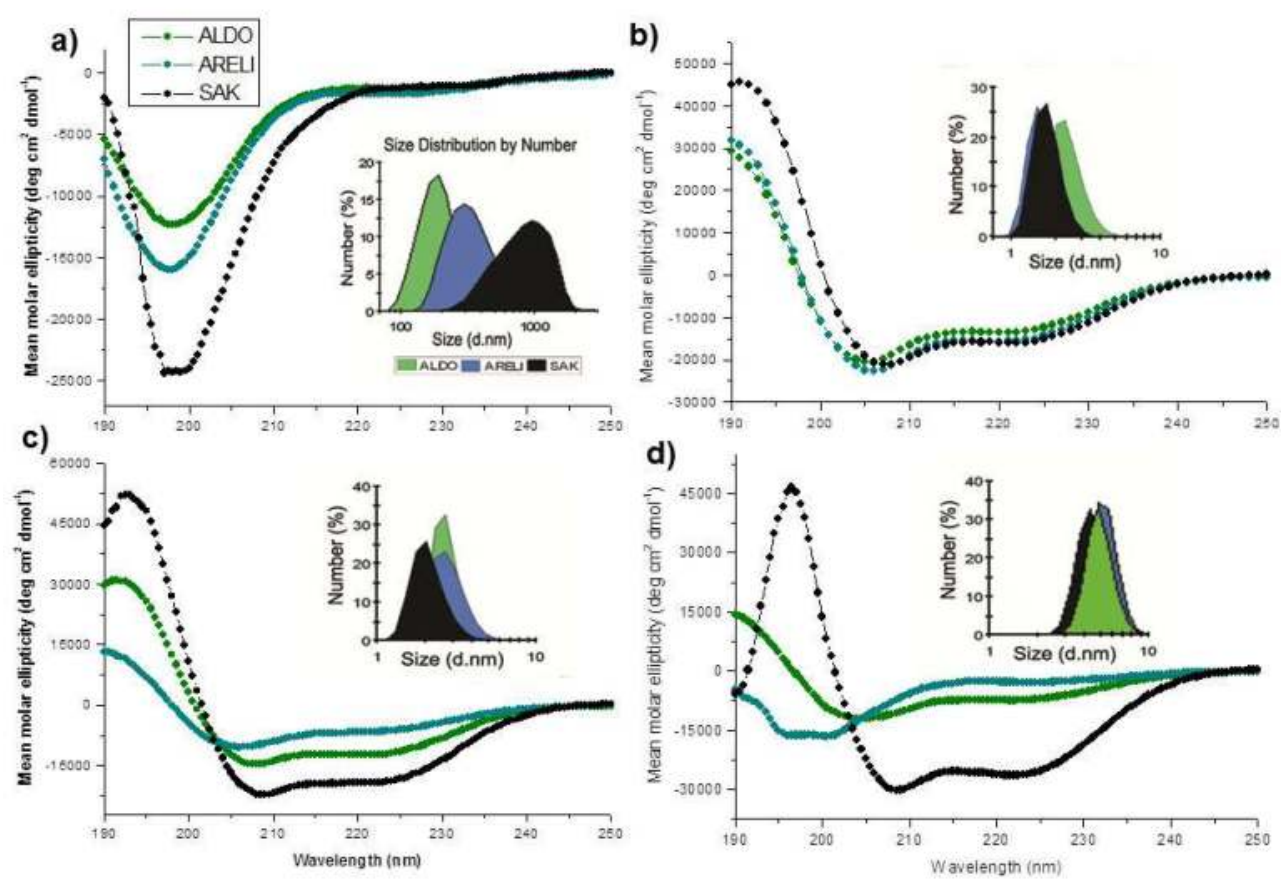

Fig. 7. Far-UV CD data of Apo CI-derived peptides. a) Spectra recorded in water for peptides ALDO, ARELI, and SAK. b) In the presence of $40 \% \mathrm{v} / \mathrm{v}$ TFE. c) In the presence of SDS $(20 \mathrm{mM})$. d) In the presence of lyso- $\mathrm{C}_{12} \mathrm{PC}(20 \mathrm{mM})$. Insets: DLS analysis of the same corresponding peptide solutions employed for $\mathrm{CD}$ experiments. Adapted from (MendozaEspinosa et al., 2008).

Tests performed with 1-hexanoyl-2-hydroxy-sn-glycero-3-phosphocholine (lyso- ${ }_{6} \mathrm{PC}$ ) do not promote any change in the secondary structure of all peptides studied (data not shown). However, in the presence of 1-lauroyl-2-hydroxy-sn-glycero-3-phosphocholine (lyso- $\mathrm{C}_{12} \mathrm{PC}$ ), peptides corresponding to the $\mathrm{N}$-terminal (ALDO) and C-terminal (SAK) segments acquired different percentages of a-helix structure as a function of the lysophospholipid concentration. ALDO was the peptide less sensitive to lyso- $\mathrm{C}_{12} \mathrm{PC}$, however, the effect of this lysophospholipid is greater than that generated by SDS. On the other hand, SAK presented disorder-to-order transitions from the lowest levels of lyso- $\mathrm{C}_{12} \mathrm{PC}$. Greater effect was observed for this lipid on this peptide compared to the one observed with SDS and TFE molecules (see Fig. 7d). Interestingly DLS experiments showed that peptide solutions with 
pure water and lyso- $\mathrm{C}_{6} \mathrm{PC}$ in which there was no disorder-order transitions, presented aggregates in solution. In contrast, for the peptides-lyso- $\mathrm{C}_{12} \mathrm{PC}$ solutions that generated disorder-to-order transition and the promotion of a well-defined a-helical conformation, allows the association of lipid/peptide molecules in such an orderly fashion that the system avoids aggregation. It is interesting to note that while lyso- $\mathrm{C}_{6} \mathrm{PC}$ aggregates increase in size in the presence of peptides for the case of lyso- $\mathrm{C}_{12} \mathrm{PC}$ the size does not change with or without the same peptides (see Fig. 8).

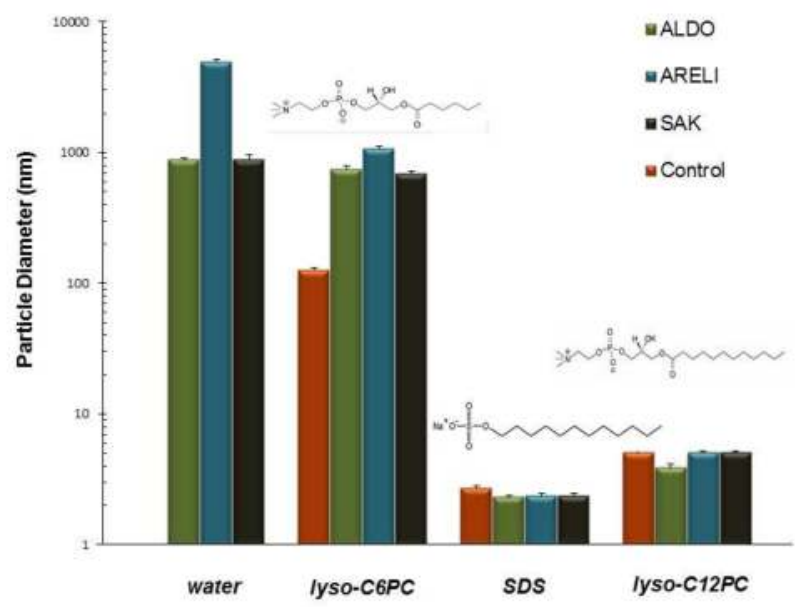

Fig. 8. Dynamic light scattering of Apo CI peptides associated with lysophospholipids of different acyl-chain lengths. a) Quantification of particle diameters given by peptide/lipid aggregates in the presence of SDS $(20 \mathrm{mM})$, lyso- $\mathrm{C}_{6} \mathrm{PC}(20 \mathrm{mM})$ and lyso- $\mathrm{C}_{12} \mathrm{PC}(20 \mathrm{mM})$. Adapted from (Mendoza-Espinosa et al., 2008).

Based on data obtained in this study, we have elucidated a mechanism by which the Apo CI could be functioning as a molecular switch on the surface of HDL. In this scenario we propose that Apo CI responds to a decrease in lateral pressure on the surface of HDL, which is given by an increase of cholesterol ester in the nucleus (Frank \& Marcel, 2000), by promoting its C-terminal segment to the polar/nonpolar interface of the lipoprotein particle with a concomitant change from a disordered structure to an a-helix. The fact that the surface of lipoproteins and certain types of membranes are associated with the presence of molecules such as lyso- $\mathrm{C}_{12} \mathrm{PC}$ could generate dramatic disorder-to-order transitions in the Cterminal segment of Apo CI. In consequence, these conformational changes generated by Apo CI could be related to the biological activity of molecules such as esphingosine 1 phosphate that when associated with HDL particles it has been observed that promotes an anti-inflammatory effect and therefore presents a potential role as atheroprotective (JerzyRoch \& Assman, 2005). 
Also, since cholesterol esters formed by the enzyme lecithin-cholesterol acyltransferase (LCAT) located at the surface of HDL particles promotes the transfer of a fatty acyl group from position two of phosphatidylcholine to cholesterol, with the consequent synthesis of lysophosphatidylcholine, it is possible that the presence of new $\mathrm{OH}$ groups at the polar/non-polar interface change the electrostatic properties of the interface and the way water is displaced from the interface during peptide folding. In fact, it has been proposed that in the presence of lipids, the process of peptide folding corresponds to an enthalpy driven process supported by the energy employed for water displacement (Rozek et al., 1997). Localized changes in secondary structure of a number of proteins have been found to be physiologically relevant (Chakrabartty \& Baldwin, 1995; Meador et al., 1992). Therefore, a series of conformational switches have been proposed, in specific cases, to promote protein activation (Wei et al., 1994) and folding (Hamada et al., 1996). In order to find out the mechanism by which lyso- $\mathrm{C}_{12} \mathrm{PC}$ is required to induce an important conformational change, further investigation is needed. These important changes might be important in the understanding of the mechanisms Apo $\mathrm{CI}$ employs to modulate protein/protein recognition directly related to enzyme activation and modulation of Apo $\mathrm{E}$ and the cholesterol ester transfer protein (CETP) function when associated to the surface of HDL particles. Our proposal of a lipid dependant disorder-to-order conformational transition in Apo CI might be considered a conformational switch mediating enzyme activation and lipid transport. This possibility opens new ways to visualize the concert of events that take place at the surface of HDL during their transformation from early protein/lipid discoidal aggregates to spherical particles, ready to be taken up by liver cells. Further investigation of this potential mechanism designed to recognize and promote localized secondary structure conformations in proteins, undoubtedly will provide an improvement to better comprehend the protein function at the surface of lipoproteins.

\subsection{Apo Al-lipid interactions}

Several studies have evaluated the lipid-binding propensity of each of the helices composing Apo AI, noting that the N-terminal domain determines the open or closed structure of the protein when modulated by the presence of cholesterol obtained by interacting with the ATP-binding cassette (ABC) A1 (ABCA1) giving rise to the nascent HDL. Likewise, due to its high hydrophobicity, the C-terminal domain of Apo AI facilitates anchoring to lipid membranes (Fang et al., 2003; Kono et al., 2008). These studies are based on the widely accepted model for discoidal HDL, which corresponds to a disk made of a lipid bilayer surrounded by two Apo AI helices with its long axis perpendicular to the acyl chains of phospholipids (Garda, 2007). These properties can be easily observed in the hydrophobicity profile of Apo AI obtained with the use of the EMBOSS Pepinfo algorithm, employing a window of 9 amino acids and the scale of Kyte J. \& Doolittle R. F. (Kyte \& Doolittle, 1982) (see Fig. 9a). While its negative profile is characteristic of membrane proteins at the $\mathrm{N}$ and C-terminal regions of the protein (10-17, 213-229), the positive profile indicates the hydrophobic ones. On the other hand, the use of the Hydrophobic Cluster Analysis (HCA) server, which predicts hydrophobic blocks depending on the secondary structure of the polypeptide chain, shows three highly hydrophobic segments (aa 13-22, 45-49, 216-232) (Fig. 9a, hydrophobic clusters) (Callebaut et al., 1997). The distribution in the helix of negatively charged, positive or neutral aminoacids, generates the different types of helices 
present in the Apo AI. This change in the distribution of amino acids is important in the understanding of the way the protein associates with lipids (Segrest et al., 1992). For example, segments corresponding to helices 1-2 (A-type helices) and 9-10 (Y-type helices) are those with the greatest affinity for lipids, which are particularly high in the latter (Mishra et al., 1998).

Interestingly, in two SDSL-EPR spectroscopic studies (electron paramagnetic spin-label resonance spectroscopy), $\beta$-type segments were also detected in the $\mathrm{N}$-and C-terminal domains of Apo AI (Lagerstedt et al., 2007; Oda et al., 2003). The possibility of having secondary structure conformational changes has been also observed in other proteins. For instance, the fusogenic HA2 unit of hemagglutinin of the influenza virus has been shown to present these types of conformational transitions. HA2 corresponds to a segment containing 36 amino acids, that presents the ability to carry out transitions from a random coil structure to an a-helix domain. The presence of these secondary structure conformational changes in Apo AI in the presence of lipid could serve as a mechanism to decrease the energy barrier in their interaction with these molecules, a crucial step in the flow of cholesterol and assembly of HDL (Oda et al., 2003; Tamm, 2003).

\subsection{Intrinsic disorder in Apo Al}

On the other hand, Apo AI is considered within the group of natively unstructured proteins (Uversky et al., 2000). Recently, this type of protein has taken a major importance when giving rise to the term "unfoldomics". A highly dysfunctional group of proteins has been associated with a number of conditions such as amyloidosis, cancer, diabetes, neurodegenerative diseases and others. The altered sites contained in many disordered proteins have been shown to be highly susceptible to proteolysis. In the lipid-free Apo AI, specifically the N-terminal segment has been observed by various techniques such as NMR, EPR that mobility presents a great variability in their secondary structure (Kono et al., 2008; Lagerstedt et al., 2007; Okon et al., 2001, 2002; Wang et al., 1996, 1997). Using the PONDR server with the native sequence of the native Apo AI it was estimated a high percentage of disorder for five segments of Apo AI (Fig. 9b). The first segment (aa 1-10) corresponds to a site that could serve as a lipid sensor when the Apo AI is in the discoidal particle (Kono et al., 2008; Wu et al., 2007). The second site (aa 69-89) has a particularly negative charge distribution compared to the other un-structured sites (Fig 9c). The site also includes a transition between a helix type A to a type $\mathrm{Y}$, which has been postulated could be a destabilizing factor in the continuity of the secondary structure of an a-helix. Wu Z. et al (Wu et al., 2007) have proposed a discoidal HDL model where the third and longest disordered segment (aa 116-150) presents a region that could be considered as a hinge. The same model includes a loop (159-180) that corresponds to the fourth disordered segment (aa 172-194). Also, this site is adjacent to the segment postulated to be the one that interacts with LCAT (aa 159-170). The fifth disordered segment is located close to a transition region from a helix type A to a type Y. Although the latter site presents an a-helix structure in the crystal structure of Apo AI, by EPR tests this segment shows a $\beta$-structure that could serve as a mechanism to facilitate the interaction with lipids. Interestingly, very low concentrations of amyloid fibrils formed by a segment of $10 \mathrm{kD} \mathrm{N}$-terminus of native Apo AI, have been found in vivo (Schmidt et al., 1997). These structures are constituted by $\beta$-cross structures 
that in turn produce $\beta$-strands oriented in a perpendicular way with respect to the long axis of the fiber, resulting in its increased spreading capacity. Subsequently, protofibrils associate laterally or rotate together to form fibers of larger diameter (DuBay et al., 2004).

In our laboratory by their structural and perhaps biological importance, we have analyzed three peptides designed according to the sequence reported for the native Apo AI and its crystal structure (Borhani et al., 1997). These peptides are DRV (D9-D24) and KLL (K45-Q63) located within its N-terminal helical segments, and VLES (V221-K239) located in a Cterminal segment. By sequence analysis of native Apo AI employing the Zyggregator server (Tartaglia et al., 2008), it has been observed that this protein presents several sites with the propensity to form amyloid fibrils (A15-D20, W50-F57 and S224-L230), which interestingly enough are included in peptide sequence DRV, KLL and VLES (Fig. 9d, Zagg Propensity). This server uses an algorithm that considers patterns of hydrophobicity, polar amino acids
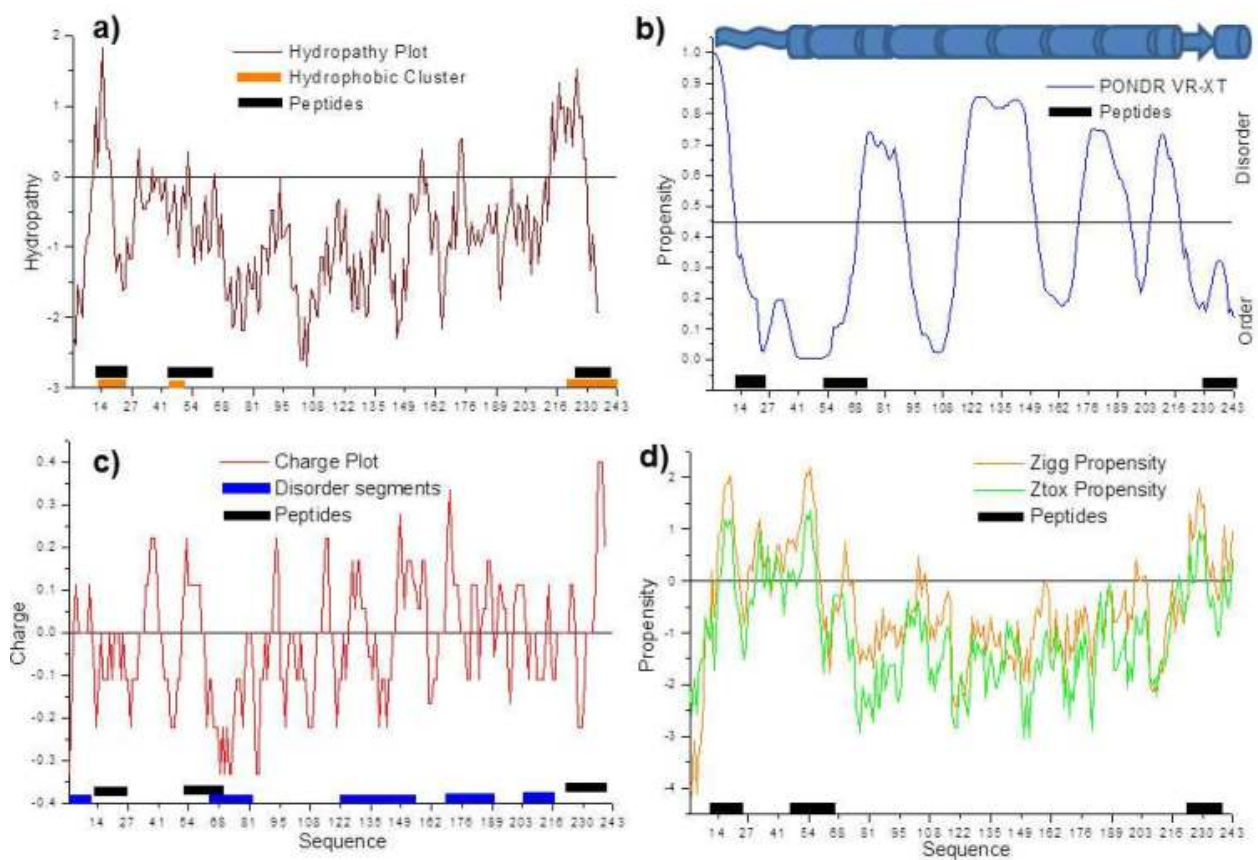

Fig. 9. Methods employed in the prediction of disorder, aggregation and propensity of amyloid fiber formation based on the sequence of native Apo AI. a) Hydrophobicity profile calculated with the EMBOSS server: Pepinfo, using a window of 9 aa and scale of Kyte \& Doolittle hydrophobicity, red line. Hydrophobic segments calculated with the HCA server, orange box. Peptide position DRV, KLL and VLES in the sequence of Apo AI, black box. b) Profile of disorder determined by the PONDR server (PONDR VL-XT). c) Load profile calculated with the EMBOSS server: Charge using a window of 9 aa. d) Propensity of amyloid fiber formation with the Zyggregator server (Zagg Propensity) and formation of globular structures (Ztox Propensity). 
and aromatic content observed in polypeptide chains of amyloidogenic proteins. The segments prone to aggregation in the Apo AI present sequences of highly hydrophobic blocks composed of six to seven amino acids flanked by negative and/or positive charges. On the other hand, Zyggregator calculates the tendency to form globular structures, which have been observed to be a step in the formation of amyloidogenic fibers. It has been observed with in vitro experiments that these globular structures formed by amyloid peptides are involved in a process of cellular cytotoxicity due the formation of pores in membranes (Lashuel \& Lansbury, 2006). The patterns to form amyloid structures in Apo AI calculated by Zyggregator, show the same one that is observed during the formation of amyloid fibers (Fig. 9d, Ztox propensity).

\subsection{Amyloidogenic Apo Al}

Interestingly, within the existing mutants of Apo AI, there are 4 isoforms associated with systemic forms of hereditary amyloidosis. Mutations correspond to Gly26-Arg, Leu60-Arg, Trp50-Arg and a deletion/insertion of segment (Leu60-Phe71) - (Val-Val-Thr). Considering the structure for the lipid-free Apo AI proposed by Ajees et al., these mutations generally provide positive charges to the hydrophobic interface formed between the two pairs of helices at the N-terminal segment (aa 1-188). The introduction of a polar amino acid residue by the amyloidogenic mutations in the hydrophobic interface of the lipid-free Apo AI, probably prevents the formation of the cluster of a-helices in the N-terminal structure. This also hinders the formation of hydrophilic patches located in different areas of the protein (see Fig. 10) (Oram, 2002). These hydrophilic patches have been postulated to interact with ABCA1 for the transfer of phospholipid and cholesterol. One consequence of this obstacle might be that the formation of a properly sized discoidal HDL needed to interact with the enzyme LCAT, as observed in these mutations, is not properly achieved (Fang et al., 2003; Genschel et al., 1998). This interaction is crucial in the transition from discoidal to spherical HDL (Calabresi \& Franceschini, 2010). Discoidal HDL formed by one of the several isoforms of the amyloidogenic Apo AI known nowadays, are rapidly catabolized and do not become spherical HDL (Genschel et al., 1998). At this stage, it is interesting to mention that the metabolic pathway of these Apo AI isoforms that cause deposition of amyloid fibrils, has not yet been clarified. However any of these mutations found in helix 1 and helix $G$ * of Apo AI could be generating a loop susceptible to proteolysis between helices 2 and 3 (Apo AI disordered second site with low affinity to lipid profile and with a distinctly negative charge) (Figs. 9b and 9c). In all cases, amyloid fibers are generated with polypeptides from the first 83-94 amino acids at the N-terminus of Apo AI. Mutations at amino acids 26, 50 and 60 also generate charge changes, characteristic that favors the formation of extended $\beta$ sheets (García-González \& Mas-Oliva, 2011). These peptides released regardless of the origin of the mutation, always have the same net charge, indicating the conservation of the hydrophilic profile. Likewise, the hydrophobic moment value and the average total hydrophobicity decrease in the mutations with respect to native sequences.

It is remarkable that several theoretical and experimental data related to several $\mathrm{N}$-terminal and C-terminal segments of Apo AI indicate that both have a high propensity for aggregation. However, only the first one was found in the amyloidogenic plaques isolated from familial amyloidosis or Alzheimer-affected people. Segments of Apo AI with a tendency to be maintained in a disordered state, together with their low affinity sites for 
lipid, could be the key for the understanding of HDL particles formation. Due to these characteristics, it seems Apo AI has the ability to modulate its secondary structure based on the presence of hydrophobic/hydrophilic interfaces that in turn might activate or inhibit the function of proteins that regulate the metabolism of HDL.

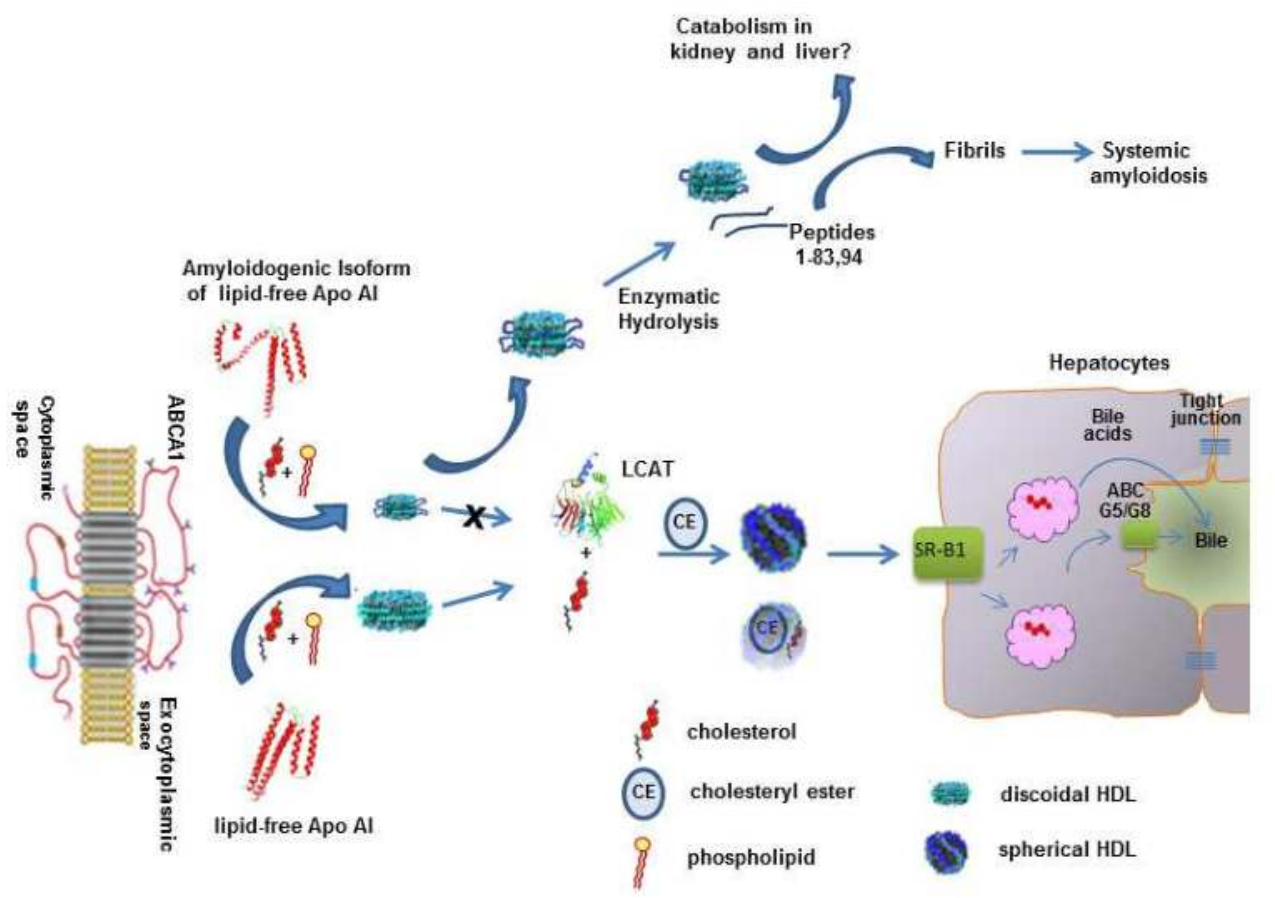

Fig. 10. The ABCA1 receptor promotes the transfer of phospholipids to a lipid-poor form of native Apo AI native, the major component of HDLs. The mechanism by which this process occurs is not fully understood; probably ABCA1 translocates phospholipids and cholesterol from the plasma membrane to HDL Apo AI producing a discoidal particle. These discoidal particles are transformed into spherical HDLs in the blood by the action of the enzyme LCAT. Spherical HDLs associate with the SRB1 receptor in the plasma membrane of hepatocytes and transfer free and esterified cholesterol to the liver for excretion into the bile as free cholesterol (via ABCG5/G8) or subsequent conversion to bile salts (Oram, 2002). In the case of the formation of amyloidogenic isoforms of Apo AI, a proper interaction with ABCA1 is impeded and therefore the formation of discoidal HDLs becomes a deficient process, with the consequent problems in the recognition of LCAT and also SR-B1. It is known that abnormal HDLs are rapidly catabolized releasing different peptides that in turn generate peptides that form amyloid fibers that might initiate a systemic amyloidosis.

\section{Conclusions}

We believe conformational changes observed in monolayers of Apo CI and AII during lateral compression could be of direct relevance to changes in surface tension at the surface 
of lipoproteins. Thus, in response to changes in surface tension of the lipoprotein particle, Apolipoproteins could present structural changes. Interestingly, our working hypothesis is of relevance when extrapolated to the conformational changes observed at the lipid/plasma interface at the surface of a lipoprotein particle. In this case, because of the small size and rich protein composition of discoidal HDL (pre-2HDL $\beta$ ) it is proposed that the lateral pressure in the phospholipid monolayer of these particles is most likely to be high and only decreases in parallel with changes in size and shape of these lipoproteins when they begin to accumulate cholesterol esters to form HDL spherical (a-HDL). The results of our studies employing Apos allow us to postulate that the lateral pressure of the phospholipids monolayer associated with proteins on the surface of the different HDL particles may be very different depending on their size and shape.

In addition, the fact that these Apos could present a different conformation from newly synthesized lipoproteins with a discoidal form to a mature state with a spherical shape could be an important factor in the understanding of their physiological properties such as directionality and receptor recognition. However, the ways in which structural changes induced by lipid interaction modulate the functionality of these Apos are still to be clarified, since the formation of amyloidogenic forms for several segments of these Apos, as presented in this chapter, have also been found to play a critical role in their structure/function relationship.

Currently, the understanding of the mechanisms by which segments, entire native or mutated proteins get transformed into amyloid-like structures, has resulted to be a challenge. Since several disorder-to-order transitions in proteins have been found to be reversible, this phenomenon has been frequently associated with important signaling events in the cell. Due to the central role of this phenomenon in cell biology, protein misfolding and aberrant conformational transitions have been at present associated with an important number of diseases. Nevertheless, differences between "functional" and "pathological" disorder-to-order or order-to-disorder transitions that might lead to the formation of amyloids, might simply reside in the modulatory pathways involved along their synthesis and the environment proteins or protein segments are placed into.

\section{Acknowledgment}

Research described in the present chapter has been supported by Consejo Nacional de Ciencia y Tecnología (CONACYT), Red Temática de Materia Condensada Blanda (CONACYT), DGAPA-UNAM (Universidad Nacional Autónoma de México) and UAM (Universidad Autónoma Metropolitana).

\section{References}

Ajees, A.A., Anantharamaiah, G.M., Mishra, V.K., Hussain, M.M. \& Murthy, H.M. (2006). Crystal Structure of Human Apolipoprotein A-I: Insights into Its Protective Effect against Cardiovascular Diseases. Proceedings of the National Academy of Sciences of the United States of America, Vol. 103, No. 7, (February 2006), pp. 2126-2131, ISSN 0027-8424

Andreola, A., Bellotti, V., Giorgetti, S., Mangione, P., Obici, L., Stoppini, M., Torres, J., Monzani, E., Merlini, G. \& Sunde, M. (2003). Conformational Switching and 
Fibrillogenesis in the Amyloidogenic Fragment of Apolipoprotein A-I. The Journal of Biological Chemistry, Vol. 278, No. 4, (January 2003), pp. 2444-2451, ISSN 00219258

Bode, W. \& Huber, R. (1976). Induction of the Bovine Trypsinogen-Trypsin Transition by Peptides Sequentially Similar to the N-Terminus of Trypsin. Federation of European Biochemical Societies Letters, Vol. 68, No. 2, (October 1976), pp. 231-236, ISSN 00145793

Bolaños-García, V.M., Mas-Oliva, J., Ramos, S. \& Castillo, R. (1999). Phase Transitions in Monolayers of Human Apolipoprotein C-I. Journal of Physical Chemistry B, Vol. 103, No. 30, (July 1999), pp. 6236-6242, ISSN 1089-5647

Bolaños-García, V.M., Ramos, S., Xicohtencatl-Cortes, J., Castillo, R. \& Mas-Oliva, J. (2001). Monolayers of Apolipoproteins at the Air/Water Interface. Journal of Physical Chemistry B, Vol. 105, No. 24, (June 2001), pp. 5757-5765, ISSN 1089-5647

Bolaños-Garcia, V.M., Soriano-Garcia, M. \& Mas-Oliva, J. (1997). CETP and Exchangeable Apoproteins: Common Features in Lipid Binding Activity. Molecular and Cellular Biochemistry, Vol. 175, No. 1-2, (October 1997), pp. 1-10, ISSN 0300-8177

Borhani, D.W., Rogers, D.P., Engler, J.A. \& Brouillette, C.G. (1997). Crystal Structure of Truncated Human Apolipoprotein A-I Suggests a Lipid-Bound Conformation. Proceedings of the National Academy of Sciences of the United States of America, Vol. 94, No. 23, (November 1997), pp. 12291-12296, ISSN 0027-8424

Brewer, H.B., Jr., Lux, S.E., Ronan, R. \& John, K.M. (1972). Amino Acid Sequence of Human ApoLp-Gln-II (ApoA-II), an Apolipoprotein Isolated from the High-Density Lipoprotein Complex. Proceedings of the National Academy of Sciences of the United States of America, Vol. 69, No. 5, (May 1972), pp. 1304-1308, ISSN 0027-8424

Brewer, H.B., Jr., Ronan, R., Meng, M. \& Bishop, C. (1986). Isolation and Characterization of Apolipoproteins A-I, A-II, and A-IV. Methods In Enzymology, Vol. 128, (1986), pp. 223-246, ISSN 0076-6879

Burkett, S.L. \& Read, M.J. (2001). Adsorption-Induced Conformational Changes of a-Helical Peptides. Langmuir: The ACS Journal of Surfaces and Colloids, Vol. 17, No. 16, (July 2001), pp. 5059-5065, ISSN 0743-7463

Bustos, D.M. \& Iglesias, A.A. (2006). Intrinsic Disorder is a Key Characteristic in Partners that Bind 14-3-3 Proteins. Proteins, Vol. 63, No. 1, (April 2006), pp. 35-42, ISSN 10970134

Calabresi, L. \& Franceschini, G. (2010). Lecithin:Cholesterol Acyltransferase, High-Density Lipoproteins, and Atheroprotection in Humans. Trends in Cardiovascular Medicine, Vol. 20, No. 2, (February 2010), pp. 50-53, ISSN 1873-2615

Callebaut, I., Labesse, G., Durand, P., Poupon, A., Canard, L., Chomilier, J., Henrissat, B. \& Mornon, J.P. (1997). Deciphering Protein Sequence Information through Hydrophobic Cluster Analysis (HCA): Current Status and Perspectives. Cellular and Molecular Life Sciences : CMLS, Vol. 53, No. 8, (August 1997), pp. 621-645, ISSN 1420$682 X$

Campos-Terán, J., Mas-Oliva, J. \& Castillo, R. (2004). Interactions and Conformations of aHelical Human Apolipoprotein CI on Hydrophilic and on Hydrophobic Substrates. Journal of Physical Chemistry B, Vol. 108, No. 52, (November 2004), pp. 20442-20450, ISSN 1089-5647 
Castro, G.R. \& Fielding, C.J. (1984). Evidence for the Distribution of Apolipoprotein E between Lipoprotein Classes in Human Normocholesterolemic Plasma and for the Origin of Unassociated Apolipoprotein E (Lp-E). Journal of Lipid Research, Vol. 25, No. 1, (January 1984), pp. 58-67, ISSN 0022-2275

Chakrabartty, A. \& Baldwin R.L (1995). Stability of a-Helices. Advances in Protein Chemistry, Vol. 46, (1995), pp. 141-176, ISSN 0065-3233

Chan, D.Y.C., Pashley, R.M. \& White, L.R. (1980). A Simple Algorithm for the Calculation of the Electrostatic Repulsion between Identical Charged Surfaces in Electrolyte. Journal of Colloid and Interface Science, Vol. 77, No. 1, (September 1980), pp. 283-285, ISSN 0021-9797

Claesson, P.M., Blomberg, E., Fröberg, J.C., Nylander, T. \& Arnebrant, T. (1995). Protein Interactions at Solid Surfaces. Advances in Colloid and Interface Science, Vol. 57, (May 1995), pp. 161-227, ISSN 0001-8686

Clay, M.A., Cehic, D.A., Pyle, D.H., Rye, K.A. \& Barter, P.J. (1999). Formation of Apolipoprotein-Specific High-Density Lipoprotein Particles from Lipid-Free Apolipoproteins A-I and A-II. Biochemical Journal, Vol. 337 (February 1999), pp. 445451, ISSN 0264-6021

Conchillo-Solé, O., de Groot, N.S., Aviles, F.X., Vendrell, J., Daura, X. \& Ventura, S. (2007). Aggrescan: A Server for the Prediction and Evaluation of "Hot Spots" of Aggregation in Polypeptides. BMC Bioinformatics, Vol. 8, (February 2007), pp. 65, ISSN 1471-2105

Cortese, M.S., Uversky, V.N. \& Dunker, A.K. (2008). Intrinsic Disorder in Scaffold Proteins: Getting More from Less. Progress in Biophysics and Molecular Biology, Vol. 98, No. 1, (September 2008), pp. 85-106, ISSN 0079-6107

Dalal, S. \& Regan, L. (2000). Understanding the Sequence Determinants of Conformational Switching Using Protein Design. Protein Science : A Publication of the Protein Society, Vol. 9, No. 9, (September 2000), pp. 1651-1659, ISSN 0961-8368

Despres, J.P., Lemieux, I., Dagenais, G.R., Cantin, B. \& Lamarche, B. (2000). HDL-Cholesterol as a Marker of Coronary Heart Disease Risk: The Quebec Cardiovascular Study. Atherosclerosis, Vol. 153, No. 2, (December 2000), pp. 263-272, ISSN 0021-9150

Dobson, C.M. (1999). Protein Misfolding, Evolution and Disease. Trends in Biochemical Sciences, Vol. 24, No. 9, (September 1999), pp. 329-332, ISSN 0968-0004

Dobson, C.M. (2003). Protein Folding and Misfolding. Nature, Vol. 426, No. 6968, (December 2003), pp. 884-890, ISSN 1476-4687

Dobson, C.M. (2004). Protein Chemistry. In the Footsteps of Alchemists. Science, Vol. 304, No. 5675, (May 2004), pp. 1259-1262, ISSN 1095-9203

Dubay, K.F., Pawar, A.P., Chiti, F., Zurdo, J., Dobson, C.M. \& Vendruscolo, M. (2004). Prediction of the Absolute Aggregation Rates of Amyloidogenic Polypeptide Chains. Journal of Molecular Biology, Vol. 341, No. 5, (August 2004), pp. 1317-1326, ISSN 0022-2836

Dunker, A.K., Garner, E., Guilliot, S., Romero, P., Albrecht, K., Hart, J., Obradovic, Z., Kissinger, C. \& Villafranca, J.E. (1998). Protein Disorder and the Evolution of Molecular Recognition: Theory, Predictions and Observations. Pacific Symposium on Biocomputing, Vol. 3, (August 1998), pp. 473-484, ISSN 1793-5091 
Dunker, A.K., Lawson, J.D., Brown, C.J., Williams, R.M., Romero, P., Oh, J.S., Oldfield, C.J., Campen, A.M., Ratliff, C.M., Hipps, K.W., Ausio, J., Nissen, M.S., Reeves, R., Kang, C., Kissinger, C.R., Bailey, R.W., Griswold, M.D., Chiu, W., Garner, E.C. \& Obradovic, Z.J. (2001). Intrinsically Disordered Protein. Journal of Molecular Graphics and Modelling, Vol. 19, No. 1, (February 2001), pp. 26-59, ISSN: 1093-3263

Eaton, W.A., Muñoz, V.,Hagen, S.J., Jas, G.S., Lapidus, L.J. \& Henry, E.R. (2000). Fast Kinetics and Mechanisms in Protein Folding. Annual Review of Biophysics and Biomolecular Structure, Vol. 29, (June 2000), pp. 327-359, ISSN: 1056-8700

Eggerman, T.L., Hoeg, J.M., Meng, M.S., Tombragel, A., Bojanovski, D. \& Brewer, H.B., Jr. (1991). Differential Tissue-Specific Expression of Human ApoA-I and ApoA-II. Journal of Lipid Research, Vol. 32, No. 5, (May 1991), pp. 821-828, ISSN 0022-2275

Eisenberg, D., Nelson, R., Sawaya, M.R., Balbirnie, M., Sambashivan, S., Ivanova, M.I., Madsen, A.O. \& Riekel, C. (2006). The Structural Biology of Protein Aggregation Diseases: Fundamental Questions and Some Answers. Accounts of Chemical Research, Vol. 39, No. 9, (September 2006), pp. 568-575, ISSN 0001-4842

Eisenberg, S. (1990). Metabolism of Apolipoproteins and Lipoproteins. Current Opinion in Lipidology, Vol. 1, No. 3, (June 1990), pp. 205-215, ISSN 0957-9672

Fang, Y., Gursky, O. \& Atkinson, D. (2003). Lipid-Binding Studies of Human Apolipoprotein A-I and its Terminally Truncated Mutants. Biochemistry, Vol. 42, No. 45, (November 2003), pp. 13260-13268, ISSN 0006-2960

Fink, A.L. (1998). Protein Aggregation: Folding Aggregates, Inclusion Bodies and Amyloid. Folding \& Design, Vol. 3, No. 1, (February 1998), pp. R9-23, ISSN 1359-0278

Frank, P.G. \& Marcel, Y.L. (2000). Apolipoprotein A-I: Structure-Function Relationships. Journal of Lipid Research, Vol. 41, No. 6, (June 2000), pp. 853-872, ISSN 0022-2275

García-González, V. \& Mas-Oliva, J. (2011). Amyloidogenic Properties of a D/N Mutated 12 Amino Acid Fragment of the C-Terminal Domain of the Cholesteryl-Ester Transfer Protein (CETP). International Journal of Molecular Sciences, Vol. 12, No. 3, (March 2011), pp. 2019-2035, ISSN 1422-0067

Garda, H.A. (2007). Structure-Function Relationships in Human Apolipoprotein A-I: Role of a Central Helix Pair. Future Lipidology, Vol. 2, No. 1, (February 2007), pp. 95-104, ISSN 1746-0875

Genschel, J., Haas, R., Pröpsting, M.J. \& Schmidt, H.H.J. (1998). Hypothesis. Apolipoprotein A-I Induced Amyloidosis. Federation of European Biochemical Societies Letters, Vol. 430, No. 3, (July 1998), pp. 145-149, ISSN 0014-5793

Gsponer, J. \& Vendruscolo, M. (2006). Theoretical Approaches to Protein Aggregation. Protein and Peptide Letters, Vol. 13, No. 3, (March 2006), pp. 287-293, ISSN 0929-8665

Hamada, D., Segawa, S. \& Goto, Y. (1996). Non-Native Alpha-Helical Intermediate in the Refolding of Beta-Lactoglobulin, a Predominantly Beta-Sheet Protein. Nature Structural Biology, Vol. 3, No. 10, (October 1996), pp. 868-873, ISSN 1072-8368

Huang, K. (2005). Lectures on Statistical Physics and Protein Folding, World Scientific Publishing Company, ISBN 978-981-256-143-5, Singapore.

Huber, R. \& Bode, W. (1978). Structural Basis of the Activation and Action of Trypsin. Accounts of Chemical Research, Vol. 11, No. 3, (March 1978), pp. 114-122, ISSN 00014842 
Israelachvili, J.N. (1973). Thin Film Studies Using Multiple-Beam Interferometry. Journal of Colloid and Interface Science, Vol. 44, No. 2, (August 1973), pp. 259-272, ISSN 00219797

Israelachvili, J.N. \& McGuiggan, P.M. (1990). Adhesion and Short Range Force between Surfaces. Part I: New Apparatus for Surface Force Measurements. Journal of Materials Research, Vol. 5, No. 10, (October 1990), pp. 2223-2231, ISSN 0884-2914

James, L.C. \& Tawfik, D.S. (2003). Conformational Diversity and Protein Evolution--a 60Year-Old Hypothesis Revisited. Trends in Biochemical Sciences, Vol. 28, No. 7, (July 2003), pp. 361-368, ISSN 0968-0004

Jerzy-Roch, N. \& Assmann, G. (2005). Atheroprotective Effects of High-Density LipoproteinAssociated Lysosphingolipids. Trends in Cardiovascular Medicine, Vol. 15, No. 7, (October 2005), pp. 265-271, ISSN 1050-1738

Kekicheff, P., Ducker, W.A., Ninham, B.W. \& Pileni, M.P. (1990). Multilayer Adsorption of Cytochrome c on Mica around Isolectric pH. Langmuir, Vol. 6, No. 11 (November 1990), pp. 1704-1708, ISSN 0743-7463

Kono, M., Okumura, Y., Tanaka, M., Nguyen, D., Dhanasekaran, P., Lund-Katz, S., Phillips, M.C. \& Saito, H. (2008). Conformational Flexibility of the N-Terminal Domain of Apolipoprotein A-I Bound to Spherical Lipid Particles. Biochemistry, Vol. 47, No. 43, (October 2008), pp. 11340-11347, ISSN 1520-4995

Kriwacki, R.W., Hengst, L., Tennant, L., Reed, S.I. \& Wright, P.E. (1996). Structural Studies of P21waf1/Cip1/Sdi1 in the Free and Cdk2-Bound State: Conformational Disorder Mediates Binding Diversity. Proceedings of the National Academy of Sciences of the United States of America, Vol. 93, No. 21, (October 1996), pp. 11504-11509, ISSN 0027-8424

Kumar, M.S., Carson, M., Hussain, M.M. \& Murthy, H.M. (2002). Structures of Apolipoprotein A-II and a Lipid-Surrogate Complex Provide Insights into Apolipoprotein-Lipid Interactions. Biochemistry, Vol. 41, No. 39, (October 2002), pp. 11681-11691, ISSN 0006-2960

Kyte, J. \& Doolittle, R.F. (1982). A Simple Method for Displaying the Hydropathic Character of a Protein. Journal of Molecular Biology, Vol. 157, No. 1, (May 1982), pp. 105-132, ISSN 0022-2836

Lagerstedt, J.O., Budamagunta, M.S., Oda, M.N. \& Voss, J.C. (2007). Electron Paramagnetic Resonance Spectroscopy of Site-Directed Spin Labels Reveals the Structural Heterogeneity in the N-Terminal Domain of ApoA-I in Solution. The Journal of Biological Chemistry, Vol. 282, No. 12, (March 2007), pp. 9143-9149, ISSN 0021-9258

Lashuel, H.A. \& Lansbury, P.T., Jr. (2006). Are Amyloid Diseases Caused by Protein Aggregates That Mimic Bacterial Pore-Forming Toxins? Quarterly Reviews of Biophysics, Vol. 39, No. 2, (May 2006), pp. 167-201, ISSN 0033-5835

Liang, H.Q., Rye, K.A. \& Barter, P.J. (1995). Cycling of Apolipoprotein A-I between LipidAssociated and Lipid-Free Pools. Biochimica et Biophysica Acta, Vol. 1257, No. 1, (June 1995), pp. 31-37, ISSN 0006-3002

Mas-Oliva, J., Moreno, A., Ramos, S., Xicohtencatl-Cortes, J., Campos, J. \& Castillo, R. (2003). Monolayers of Apolipoprotein AII at the Air/Water Interface, In: Frontiers in Cardiovascular Health, Dhalla, N.S., Chockalingam, A., Berkowitz, H.I. \& Singal, 
P.K., pp. (341-352), Kluwer Academic Publishers, ISBN 978-1-4020-7451-6, Boston, U.S.A.

Meador, W.E., Means, A.R. \& Quiocho, F.A. (1992). Target Enzyme Recognition by Calmodulin: 2.4 a Structure of a Calmodulin-Peptide Complex. Vol. 257, No. 5074, (August 1992), pp. 1251-1255, ISSN 0036-8075

Mendoza-Espinosa, P., García-González, V., Moreno, A., Castillo, R. \& Mas-Oliva, J. (2009). Disorder-to-Order Conformational Transitions in Protein Structure and Its Relationship to Disease. Molecular and Cellular Biochemistry, Vol. 330, No. 1-2, (October 2009), pp. 105-120, ISSN 1573-4919

Mendoza-Espinosa, P., Moreno, A., Castillo, R. \& Mas-Oliva, J. (2008). Lipid Dependant Disorder-to-Order Conformational Transitions in Apolipoprotein CI Derived Peptides. Biochemical and Biophysical Research Communications, Vol. 365, No. 1, (January 2008), pp. 8-15, ISSN 1090-2104

Mishra, V.K., Palgunachari, M.N., Datta, G., Phillips, M.C., Lund-Katz, S., Adeyeye, S.O., Segrest, J.P. \& Anantharamaiah, G.M. (1998). Studies of Synthetic Peptides of Human Apolipoprotein A-I Containing Tandem Amphipathic Alpha-Helixes. Biochemistry, Vol. 37, No. 28, (July 1998), pp. 10313-10324, ISSN 0006-2960

Nylander, T. \& Wahlgren, M.N. (1997). Forces between Adsorbed Layers of Beta-Casein. Langmuir: The ACS Journal of Surfaces and Colloids, Vol. 13, No. 23, (November 1997), pp. 6219-6225, ISSN 0743-7463

Oda, M.N., Forte, T.M., Ryan, R.O. \& Voss, J.C. (2003). The C-Terminal Domain of Apolipoprotein A-I Contains a Lipid-Sensitive Conformational Trigger. Nature Structural Biology, Vol. 10, No. 6, (June 2003), pp. 455-460, ISSN 1072-8368

Ohnishi, S. \& Takano, K. (2004). Amyloid Fibrils from the Viewpoint of Protein Folding. Cellular and Molecular Life Sciences : CMLS, Vol. 61, No. 5, (March 2004), pp. 511-524, ISSN 1420-682X

Okon, M., Frank, P.G., Marcel, Y.L. \& Cushley, R.J. (2001). Secondary Structure of Human Apolipoprotein A-I(1-186) in Lipid-Mimetic Solution. Federation of European Biochemical Societies Letters, Vol. 487, No. 3, (January 2001), pp. 390-396, ISSN 00145793

Okon, M., Frank, P.G., Marcel, Y.L. \& Cushley, R.J. (2002). Heteronuclear NMR Studies of Human Serum Apolipoprotein A-I. Part I. Secondary Structure in Lipid-Mimetic Solution. Federation of European Biochemical Societies Letters, Vol. 517, No. 1-3, (April 2002), pp. 139-143, ISSN 0014-5793

Oram, J.F. (2002). ATP-Binding Cassette Transporter A1 and Cholesterol Trafficking. Current Opinion in Lipidology, Vol. 13, No. 4, (August 2002), pp. 373-381, ISSN 0957-9672

Parker, J.L., Christenson, H.K. \& Ninham, B.W. (1989). Device for Measuring the Force and Separation between Two Surfaces Down to Molecular Separation. Review of Scientific Instruments, Vol. 60, No. 10, (October 1989), pp. 3135-3138, ISSN 0034-6748

Ramos, S., Campos-Teran, J., Mas-Oliva, J., Nylander, T. \& Castillo, R. (2008). Forces between Hydrophilic Surfaces Adsorbed with Apolipoprotein AII Alpha Helices. Langmuir: The ACS Journal of Surfaces and Colloids, Vol. 24, No. 16, (August 2008), pp. 8568-8575, ISSN 0743-7463 
Romero, P., Obradovic, Z. \& Dunker, A.K. (2001). Intelligent Data Analysis for Protein Disorder Prediction. Artificial Intelligence Review, Vol. 14, No. 6, (December 2000), pp. 447-484, ISSN 0269-2821

Rose, G.D., Fleming, P.J., Banavar, J.R. \& Maritan, A. (2006). A Backbone-Based Theory of Protein Folding. Proceedings of the National Academy of Sciences of the United States of America, Vol. 103, No. 45, (November 2006), pp. 16623-16633, ISSN 0027-8424

Rozek, A., Buchko, G.W., Kanda, P. \& Cushley, R.J. (1997). Conformational Studies of the NTerminal Lipid-Associating Domain of Human Apolipoprotein C-I by $\mathrm{Cd}$ and $1 \mathrm{H}$ NMR Spectroscopy. Protein Science : A Publication of the Protein Society, Vol. 6, No. 9, (September 1997), pp. 1858-1868, ISSN 0961-8368

Ruíz-García, J., Moreno, A., Brezesinski, G., Möhwald, H., Mas-Oliva, J. \& Castillo, R. (2003). Phase Transitions and Conformational Changes in Monolayers of Human Apolipoprotein CI and AII. Journal of Physical Chemistry B, Vol. 107, No. 40, (September 2003), pp. 11117-11124, ISSN 1089-5647

Schmidt, H.H., Haas, R.E., Remaley, A., Genschel, J., Strassburg, C.P., Buttner, C. \& Manns, M.P. (1997). In Vivo Kinetics as a Sensitive Method for Testing Physiologically Intact Human Recombinant Apolipoprotein A-I: Comparison of Three Different Expression Systems. Clinica Chimica Acta; International Journal of Clinical Chemistry, Vol. 268, No. 1-2, (December 1997), pp. 41-60, ISSN 0009-8981

Segrest, J.P., Jones, M.K., De Loof, H., Brouillette, C.G., Venkatachalapathi, Y.V. \& Anantharamaiah, G.M. (1992). The Amphipathic Helix in the Exchangeable Apolipoproteins: A Review of Secondary Structure and Function. Journal of Lipid Research, Vol. 33, No. 2, (February 1992), pp. 141-166, ISSN 0022-2275

Sickmeier, M., Hamilton, J.A., LeGall, T., Vacic, V., Cortese, M.S., Tantos, A., Szabo, B., Tompa, P., Chen, J., Uversky, V.N., Obradovic, Z. \& Dunker, A.K. (2007). Disprot: The Database of Disordered Proteins. Nucleic Acids Research, Vol. 35, Suppl. 1, (January 2007), pp. D786-793, ISSN 1362-4962

Su, C.T., Chen, C.Y. \& Hsu, C.M. (2007). Ipda: Integrated Protein Disorder Analyzer. Nucleic Acids Research, Vol. 35, Suppl. 2, (July 2007), pp. W465-472, ISSN 1362-4962

Swaney, J.B. \& Weisgraber, K.H. (1994). Effect of Apolipoprotein C-I Peptides on the Apolipoprotein E Content and Receptor-Binding Properties of Beta-Migrating Very Low Density Lipoproteins. Journal of Lipid Research, Vol. 35, No. 1, (January 1994), pp. 134-142, ISSN 0022-2275

Tailleux, A., Duriez, P., Fruchart, J.C. \& Clavey, V. (2002). Apolipoprotein A-II, HDL Metabolism and Atherosclerosis. Atherosclerosis, Vol. 164, No. 1, (September 2002), pp. 1-13, ISSN 0021-9150

Tamm, L.K. (2003). Hypothesis: Spring-Loaded Boomerang Mechanism of Influenza Hemagglutinin-Mediated Membrane Fusion. Biochimica et Biophysica Acta, Vol. 1614, No. 1, (July 2003), pp. 14-23, ISSN 0006-3002

Tanaka, M., Koyama, M., Dhanasekaran, P., Nguyen, D., Nickel, M., Lund-Katz, S., Saito, H. \& Phillips, M.C. (2008). Influence of Tertiary Structure Domain Properties on the Functionality of Apolipoprotein A-I. Biochemistry, Vol. 47, No. 7, (February 2008), pp. 2172-2180, ISSN 0006-2960 
Tartaglia, G.G., Pawar, A.P., Campioni, S., Dobson, C.M., Chiti, F. \& Vendruscolo, M. (2008). Prediction of Aggregation-Prone Regions in Structured Proteins. Journal of Molecular Biology, Vol. 380, No. 2, (July 2008), pp. 425-436, ISSN 1089-8638

Tompa, P. (2002). Intrinsically Unstructured Proteins. Trends in Biochemical Sciences, Vol. 27, No. 10, (October 2002), pp. 527-533, ISSN 0968-0004

Uversky, V.N. (2002). What Does It Mean to Be Natively Unfolded? European Journal of Biochemistry / Federation of European Biochemical Societies, Vol. 269, No. 1, (January 2002), pp. 2-12, ISSN 0014-2956

Uversky, V.N., Gillespie, J.R. \& Fink, A.L. (2000). Why Are "Natively Unfolded" Proteins Unstructured under Physiologic Conditions? Proteins, Vol. 41, No. 3, (November 2000), pp. 415-427, ISSN 0887-3585

Wang, G. (2002). How the Lipid-Free Structure of the N-Terminal Truncated Human ApoA-I Converts to the Lipid-Bound Form: New Insights from NMR and X-Ray Structural Comparison. Federation of European Biochemical Societies Letters, Vol. 529, No. 2-3, (October 2002), pp. 157-161, ISSN 0014-5793

Wang, G.,Sparrow, J.T. \& Cushley, R.J. (1997). The Helix-Hinge-Helix Structural Motif in Human Apolipoprotein A-I Determined by NMR Spectroscopy. Biochemistry, Vol. 36, No. 44, (November 1997), pp. 13657-13666, ISSN 0006-2960

Wang, G., Treleaven, W.D. \& Cushley, R.J. (1996). Conformation of Human Serum Apolipoprotein A-I(166-185) in the Presence of Sodium Dodecyl Sulfate or Dodecylphosphocholine by 1H-NMR and CD. Evidence for Specific Peptide-SDS Interactions. Biochimica et Biophysica Acta, Vol. 1301, No. 3, (June 1996), pp. 174-184, ISSN 0006-3002

Wei, A., Rubin, H., Cooperman, B.S. \& Christianson, D.W. (1994). Crystal Structure of an Uncleaved Serpin Reveals the Conformation of an Inhibitory Reactive Loop. Nature Structural Biology, Vol. 1, No. 4, (April 1994), pp. 251-258, ISSN 1072-8368

Weinberg, R.B. \& Spector, M.S. (1985). Human Apolipoprotein A-IV: Displacement from the Surface of Triglyceride-Rich Particles by HDL2-Associated C-Apoproteins. Journal of Lipid Research, Vol. 26, No. 1, (January 1985), pp. 26-37, ISSN 0022-2275

Westermark, P., Mucchiano, G., Marthin, T., Johnson, K.H. \& Sletten, K. (1995). Apolipoprotein A1-Derived Amyloid in Human Aortic Atherosclerotic Plaques. The American Journal of Pathology, Vol. 147, No. 5, (November 1995), pp. 1186-1192, ISSN 0002-9440

Wu, Z., Wagner, M.A., Zheng, L., Parks, J.S., Shy, J.M., 3rd, Smith, J.D., Gogonea, V. \& Hazen, S.L. (2007). The Refined Structure of Nascent HDL Reveals a Key Functional Domain for Particle Maturation and Dysfunction. Nature Structural \& Molecular Biology, Vol. 14, No. 9, (September 2007), pp. 861-868, ISSN 1545-9993

Xicohtencatl-Cortes, J.,Castillo, R. \& Mas-Oliva, J. (2004b). In Search of New Structural States of Exchangeable Apolipoproteins. Biochemical and Biophysical Research Communications, Vol. 324, No. 2, (November 2004), pp. 467-470, ISSN 0006-291X

Xicohtencatl-Cortes, J.,Mas-Oliva, J. \& Castillo, R. (2004a). Phase Transitions of Phospholipid Monolayers Penetrated by Apolipoproteins. Journal of Physical Chemistry B, Vol. 108, No. 22, (April 2004), pp. 7307-7315, ISSN 1089-5647 


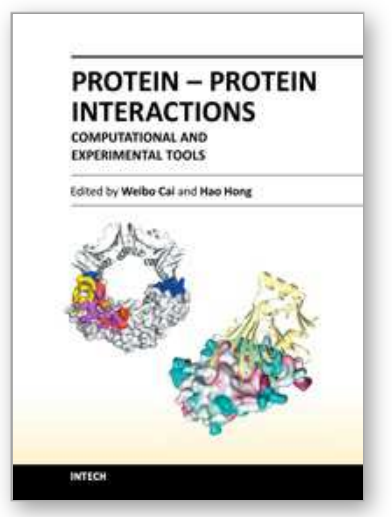

\author{
Protein-Protein Interactions - Computational and Experimental \\ Tools
}

Edited by Dr. Weibo Cai

ISBN 978-953-51-0397-4

Hard cover, 472 pages

Publisher InTech

Published online 30, March, 2012

Published in print edition March, 2012

Proteins are indispensable players in virtually all biological events. The functions of proteins are coordinated through intricate regulatory networks of transient protein-protein interactions (PPIs). To predict and/or study PPIs, a wide variety of techniques have been developed over the last several decades. Many in vitro and in vivo assays have been implemented to explore the mechanism of these ubiquitous interactions. However, despite significant advances in these experimental approaches, many limitations exist such as falsepositives/false-negatives, difficulty in obtaining crystal structures of proteins, challenges in the detection of transient PPI, among others. To overcome these limitations, many computational approaches have been developed which are becoming increasingly widely used to facilitate the investigation of PPIs. This book has gathered an ensemble of experts in the field, in 22 chapters, which have been broadly categorized into Computational Approaches, Experimental Approaches, and Others.

\title{
How to reference
}

In order to correctly reference this scholarly work, feel free to copy and paste the following:

José Campos-Terán, Paola Mendoza Espinosa, Jaime Mas and Rolando Castillo (2012). Conformational and Disorder to Order Transitions in Proteins: Structure / Function Correlation in Apolipoproteins, Protein-Protein Interactions - Computational and Experimental Tools, Dr. Weibo Cai (Ed.), ISBN: 978-953-51-0397-4, InTech, Available from: http://www.intechopen.com/books/protein-protein-interactions-computational-andexperimental-tools/conformational-and-disorder-to-order-transitions-in-proteins-structure-function-correlationin-apoli

\section{INTECH}

open science | open minds

\section{InTech Europe}

University Campus STeP Ri

Slavka Krautzeka 83/A

51000 Rijeka, Croatia

Phone: +385 (51) 770447

Fax: +385 (51) 686166

www.intechopen.com

\section{InTech China}

Unit 405, Office Block, Hotel Equatorial Shanghai

No.65, Yan An Road (West), Shanghai, 200040, China 中国上海市延安西路65号上海国际贵都大饭店办公楼 405 单元

Phone: +86-21-62489820

Fax: +86-21-62489821 
(C) 2012 The Author(s). Licensee IntechOpen. This is an open access article distributed under the terms of the Creative Commons Attribution 3.0 License, which permits unrestricted use, distribution, and reproduction in any medium, provided the original work is properly cited. 